\title{
Análise dos Traços de Tendência de Uma Amostra das Revistas Científicas da Área de Contabilidade Publicadas na Língua Inglesa
}

\author{
Prof. Dr. Fábio Frezatti \\ Doutor em Controladoria e Contabilidade - FEAVUSP \\ Professor do Departamento de Contabilidade e Atuária - FEA/USP \\ Prof. JoséAlonso Borba \\ Mestre em Contabilidade - FGV/RJ ou Doutorando em Contabilidade - \\ FEA/USP Professor do Departamento de Contabilidade - UFSC
}

RESUMO

As publicações acadêmicas são importantes pontos de sustentação do trabalho científico desenvolvido no mundo. Identificar o veículo adequado para a publicação que se pretende é uma tarefa não muito fácil, principalmente para os estudiosos oriundos de países cuja língua não seja a inglesa. Isso se verifica pela não familiaridade com as definições, critérios e procedimentos gerais que permitam o entendimento e decisão por parte do estudioso.

Nesse sentido, este artigo pretende identificar características de algumas das principais tendências observadas pelas revistas científicas que veiculam temas de interesse da classe contábil. Trata-se de um estudo exploratório com pretensões de continuidade ao longo do tempo.

Palavras-chave: revistas em lingua inglesa e publicações acadêmicas.
ABSTRACT

Academic publications are important points of support for scientific work developed all over the world. It is not so easy to identify which vehicle is adequate for the pretended publication, mainly for the researchers coming from non-English speaking countries. This can be observed by the lack of familiarity with the definitions, criteria and general procedures that enable the researcher to understand a subject and make the appropriate decisions.

In this sense, this article aims at identifying the characteristics of some of the main tendencies observed by scientific reviews dealing with accounting issues. We intend to continue this exploratory study over time.

Key Words: reviews in English, academic publication 


\section{INTRODUÇÃO}

As publicações em órgãos especializados constituem esforço importante na carreira dos pesquisadores no sentido de proporcionar a exteriorização do pensamento e produção. Num mundo globalizado, com recursos eletrônicos como aqueles de que dispomos, a comunicação se torna mais rápida, intensa, e a demanda por informações se torna muito forte no sentido de evitar perda de tempo "redescobrindo a roda", sendo de se considerar ainda a redução de prazo na geração de trabalhos e o aprimoramento do nível de uma dada pesquisa. Nessa linha de raciocínio, algumas questões são consideradas de grande importância na vida dos pesquisadores brasileiros da área contábil:

\section{Acesso à bibliografia desenvolvida em outras línguas}

Passo compulsório para que se possa trabalhar de maneira integrada com outros centros de conhecimento. Cada vez mais o trabalho de pesquisa deve refletir a visão globalizada e integrada do mundo. Isto requer identificação e familiaridade com revistas que permitam capturar essas tendências e, para alguns pesquisadores, contribuir para a seqüência da pesquisa. Não significa unicamente a preocupação em ter acesso, conhecer, analisar e utilizar revistas científicas desenvolvidas em países de línguas latinas, mas também outras línguas que permitam ao pesquisador desenvolver o seu potencial de estudo e contribuição à área de atuação. Nesse sentido, é inegável o papel da língua inglesa, embora não exclusivo, catalisando parte substancial do estado da arte em inúmeros campos do desenvolvimento científico.

\section{Acesso às bibliografias complementares e mesmo conflitantes}

Tais revistas acadêmicas têm personalidade própria em decorrência de sua origem, seu histórico, seus componentes e, mesmo, da pressão de seus leitores. A visão multidisciplinar e mesmo multifuncional é de grande utilidade para o sucesso e integração do pesquisador de uma maneira mais eclética e até específica.

\section{Possibilidade de contribuição para o progresso acadêmico}

Ao analisarmos as várias revistas, iremos perceber diferentes estágios de desenvolvimento e mesmo enfoques.

Discorrer sobre nossas peculiaridades, não apenas nos veículos nacionais, mas também nas revistas de penetração internacional, constitui passo importante para que possamos ser conhecidos, entendidos e mesmo valorizados dentro do cenário acadêmico internacional. Entender o perfil da revista é o primeiro passo para que o pesquisador possa ter chances de publicação, passando pelo processo de análise, de acordo com as regras próprias de cada veículo.

Os autores deste trabalho não pretendem esgotar o assunto, mas sim examinar uma parcela das revistas disponíveis. Neste primeiro trabalho, somente as revistas produzidas em língua inglesa foram consideradas e, mesmo assim, não se pode entender que a amostra esgote as possibilidades das revistas mais expressivas dentro do mundo acadêmico. Como conseqüência do acima exposto, a pergunta da pesquisa fica definida: Quais os principais traços de tendência das revistas cientificas da área de contabilidade publicadas em língua inglesa? A conceituação de tais traços será tratada em tópico específico deste artigo.

A perspectiva do trabalho pretende contemplar a ótica do estudioso que busca material para o desenvolvimento de suas pesquisas, tanto quanto do potencial autor que deseja publicar fora do país os resultados dos seus trabalhos. Nesse sentido, esta análise se justifica tanto pela sua importância para o pesquisador/estudioso quanto pela escassez de trabalhos sobre o assunto.

\section{CRITÉRIOS DE IDENTIFICAÇÃO DAS} REVISTAS

A identificação das revistas percorre uma série de critérios considerados úteis pelos autores. Os autores entendem que, eventualmente, e não por força da vontade, várias revistas de excelente qualidade científica podem ter sido deixadas de fora da análise a partir do critério. Este trabalho apresenta como anexos 3 tabelas com o detalhamento das informações 
obtidas em cada uma das revistas consideradas Durante o desenvolvimento da análise essas tabelas são mencionadas e devem ser consultadas pelo leitor para facilitar o entendimento. As revistas analisadas foram escolhidas a partir dos seguintes critérios:

\section{Revistas publicadas em língua inglesa, com referee.}

Esse é o critério básico observado para que a revista possa ser considerada como de utilidade acadêmica. Foram examinadas revistas dos seguintes países: Estados Unidos, Reino Unido, Canadá, República da Irlanda, Índia, Indonésia, Cingapura, Paquistão, China, Nova Zelândia e Austrália.

\section{Revistas que foram citadas em publicações, teses, dissertações e livros.}

Esse critério tem por objetivo identificar a utilidade da revista em termos do objetivo acadêmico. A biblioteca da University of Illinois at UrbanaChampaign, um centro de excelência na pesquisa contábil, foi utilizada como ponto de partida para a pesquisa e identificação das obras. Tanto Zeff (1996) como McNulty \& Boekeloo (1999) trabalham o tema recomendando o número de citações como uma forma de distinguir ou classificar revistas acadêmicas.

\section{Revistas que tratem, diretamente ou não, o tema contábil}

Levando-se em conta que o público-alvo das revistas tem identificação com o tema contábil, esta condição é sine qua non. Entretanto, não necessariamente o nome da revista contém a palavra contabilidade, controladoria, custos ou auditoria por exemplo, para se classificar dessa maneira.

A discussão sobre critérios de classificação preocupou profundamente os autores deste trabalho, já que não existe consenso sobre adequação e relação com qualidade. Dentre os vários estudiosos consultados, destacam-se Brown (1994), Englebrecht (1994), Jones (1996), Zeff (1996), Chandy (1999) e McNulty (1999). E os critérios por eles apresentados, para os objetivos exploratórios deste trabalho, não foram considerados adequados, porque tornariam o trabalho por demais direcionado, eliminando algumas possíveis fontes de informações que foram incluídas na análise e que poderão ser desconsideradas pelos leitores, se assim quiserem. Dessa maneira, a preocupação relacionada com o escolher a "melhor" revista não faz parte do escopo deste trabalho. Como conseqüência dessa abordagem, o aspecto qualitativo passa a fazer parte da análise individual de cada leitor em face de seus objetivos. Assim, foram selecionadas 118 revistas. Na tabela 1 relacionamos o nome da revista, o país onde ela é editada, a instituição responsável pela publicação e o endereço. Contudo, algumas observações devem ser feitas:

Nome do país onde é publicada/editada: Optamos por colocar o nome do país onde a revista é editada ou o nome do país dos principais editores. Salientamos que essa é uma tarefa extremamente difícil, senão impossível, visto que algumas revistas são editadas num país e publicadas em outro, enquanto outras revistas podem ter editores de dois, três ou mais países. Além do mais, é crescente o número de publicações que se intitulam de "internacionais", ou, como observado pelos pesquisadores, recebem artigos de vários países (principalmente: Estados Unidos, Canadá, Reino Unido, Austrália, Nova Zelândia, Índia, China, dentre outros). De qualquer forma, consideramos adequada a classificação, dada a perspectiva exploratória do trabalho.

Instituição responsável: Optamos por informar onde ela é editada ou publicada. No que se refere às revistas consideradas "academicamente" mais significativas, informamos também a universidade responsável pela sua edição e/ou onde seus principais editores trabalhame pesquisam atualmente.

Endereço: Optamos por um único endereço, dentro de uma seqüência de prioridade - o endereço na Internet, o e-mail da revista/editores, o número do fax ou o número do telefone. Como têm sido relativamente comuns mudanças nos endereços, acrescentamos alguns endereços principais onde pode ser encontrada uma parte considerável das revistas relacionadas neste artigo, no caso de o pesquisador se interessar por assinar ou conhecer melhor alguma. Os endereços são os seguintes:

http://www. elsevier.nl/homepage/sal/econbase/ menu.sht

http://www. anbar.co.uk/awards/acc-fin.html http://wlsevier.com/

http://www.accountingeducation.com/journals/ jnl_standing.cfm

http.//Www.imanet.org/

http://www.wkap. nl/

$\mathrm{http} / / / \mathrm{w} w \mathrm{w} . \mathrm{co}$. uk/awards/management-journals.html http://uww.anbar.co.uk/awards 


\section{TRAÇOS DE TENDÊNCIA DAS REVISTAS}

O que se percebe é que cada revista tem a sua própria personalidade. Contudo, alguns traços comuns podem ser notados e agrupamentos podem ser tentados, a fim de proporcionar condições de avaliação das revistas mais adequadas para as publicações que se possam pretender. Tais traços são importantes tanto para que o pesquisador identifique o veículo mais adequado para a sua publicação como para o estudioso que pretenda encontrar material para dar substância a uma dada pesquisa. As classificações foram feitas de maneira não-contínua no sentido de melhor aproximar a revista em termos da característica pretendida. São elas:

\section{1.Área/enfoque de interesse da revista}

Entende-se por área de interesse o tipo de assunto que se pretenda veicular. Em alguns casos, a orientação é muito superficial; em outros, o que caracteriza a revista é o público-alvo (Exemplo: pequenos negócios, área de educação etc). Na tabela 2 foi feito um breve resumo do editorial de cada revista. Quando não foi possível compreender através do editorial, expressamos nossa opinião a respeito dos tipos de artigos publicados por cada uma. Foi observada a publicação dos dois últimos anos para que se pudesse tecer alguma consideração a esse respeito. Não foi nossa intenção fazer juízo de valor do conteúdo ou da potencialidade (acadêmico ou profissional) das revistas analisadas. Resolvemos também focalizar o grau de abrangência geográfica da revista, classificada em local ou internacional. Todas a revistas que se intitulam internacionais foram assim classificadas, e assim também aquelas que mesmo não se intitulando internacionais, apresentam artigos de pesquisadores de mais de três países diferentes. As demais foram classificadas como locais, ou seja, se limitam a publicar temas sobre o âmbito do país ou de, no máximo, três países.

\section{Freqüência de publicação}

O foco referente à freqüência de publicação foi tratado na tabela 3. Obviamente, se não há uma freqüência regular, torna-se uma tarefa muito difícil classificar a revista ou periódico como um instrumento útil para pesquisa e análise. Foi definida a classificação das publicações apresentadas num horizonte de um ano ao invés de classificar por bimestre, trimestre ou quadrimestre ou semestre. Foi observado que algumas revistas têm número de publicações diferentes de ano para ano. Por exemplo, em um determinado ano elas podem publicar um suplemento ou número especial; assim, a classificação focalizou a quantidade de publicações verificadas em 1999.

\section{Dimensão de métodos quantitativos aplicados, tipos de enfoques e áreas predominantes}

Esses temas foram detalhados na tabela 3 , considerando os três tipos de classificações:

- Métodos quantitativos: procuramos classificar as revistas em três níveis: aquelas onde NORMALMENTE encontramos pouca ou nenhuma quantificação matemática ou estatística, aquelas onde encontramos razoável quantificação e, finalmente, aquelas onde a aplicação da matemática e da estatística foi por nós considerada bastante sofisticada. A diferenciação entre o segundo e terceiro tipos é qualitativa: no terceiro caso a demonstração é a essência do trabalho tanto em termos de participação como na proposta do artigo. Deve-se ressaltar aqui que as principais e mais conceituadas revistas da área contábil (Journal of Accounting Research, Accounting Review, Journal of Accounting and Economics, Contemporary Accounting Research e Accounting, Organizations and Society) empregam, invariavelmente, dosagem matemática e estatística considerada pelos autores como bastante sofisticada para os padrões normais do professor, pesquisador e profissional do Brasil.

- Tipos de enfoque: aqui as revistas foram classificadas de acordo com o enfoque normalmente empregado: empírico quando existe um forte conteúdo que procura estudar e analisar aspectos empíricos dentro de um conceito de contabilidade positiva; teórico quando existe um forte conteúdo de análise teórico e normativo; profissional quando o destaque é o conteúdo informacional, descrição e análise de normas e procedimentos, ou o relato de práticas normalmente empregadas pelas organizações; uma classificação adicional foi inevitável: teórico-empírica, em decorrência de migrações e momentos vividos. Evidentemente, tal classificação é extremamente arbitrária e pode gerar opiniões diferentes. Contudo, consideramos tal classificação como importante, ao 
menos como objeto de reflexão inicial sobre o estágio de pesquisa em contabilidade. Finalmente, vale ressaltar, é bastante difícil encontrarmos revistas que publiquem somente conteúdos teóricos ou outras que expressem somente conteúdos empíricos.

- Área predominante: As classificações consideramo foco principal de cada revista: Contabilidade Gerencial e Custos, Auditoria, Contabilidade e Mercado Financeiro, Contabilidade em Geral, Contabilidade Internacional, Fiscal e Impostos, Educação, Tecnologia e Sistemas e, finalmente, Ética.

\section{ANÁLISE DA AMOSTRA TRATADA - ALGUNS TRAÇOS DE TENDÊNCIA}

O gráfico abaixo se propõe a sumariar os aspectos mais importantes da análise qualitativa de cada revista. Contudo, ele vale individualmente e não pelo todo, já que a ponderação dos diversos elementos não deve ser apenas quantitativa.

Gráfico 1. Pontos de análise dos traços de tendência

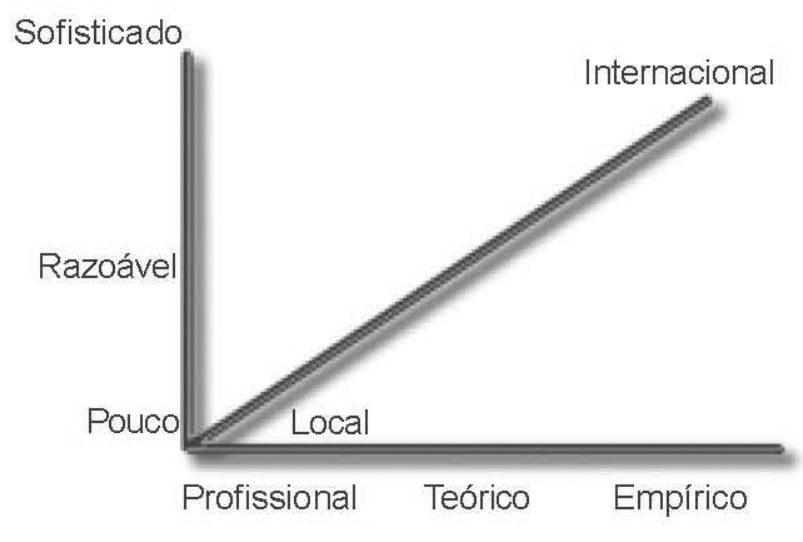

As principais considerações sobre a análise das características são as seguintes:

\section{- Localização das edições/publicações}

A grande predominância corresponde às revistas publicadas nos Estados Unidos (cerca de $61 \%$ do total) e Reino Unido (cerca de $19 \%$ do total). A conseqüência dessa caracterização é que as possibilidades de publicação vão decorrer da afinidade de trabalho desenvolvido em relação a esses países. É interessante perceber a significativa presença das editoras especializadas, juntamente com as instituições educacionais, na manutenção dessas revistas.

\section{- Abrangência geográfica}

Cerca de $53 \%$ da amostra tem enfoque internacional, ou seja, está aberta para tratar um tema que não seja estritamente local e/ou aceitar um autor de outro país que não aquele da origem da revista. A expectativa inicial era de encontrar um percentual ainda maior do que o que está sendo apresentado; entretanto, aparentemente, a tendência de crescimento das revistas internacionais é inexorável.

\section{- Freqüência de publicação}

Muito embora a distribuição seja substancialmente fragmentada, a maior distribuição fica situada entre uma a quatro vezes por ano, com preponderância para essa última. Para o pesquisador esse fator tanto é importante no sentido de achar coisas novas como também avaliar sua chance de publicação.

\section{- Enfoques perseguidos}

Os diversos traços foram considerados, sendo que a abordagem de métodos quantitativos indicou que a maior parte das revistas contém pouca ou nenhuma abordagem de métodos quantitativos (cerca de $64 \%$ do total). A segunda predominância se relaciona com aquelas revistas que têm razoável dosagem do componente relacionado com métodos quantitativos. O quesito que distingue foco profissional, teórico e empírico apresentou distribuição relativamente equilibrada entre os três, o que, em certa medida, explica os resultados obtidos no item anterior.

Finalmente, em termos de áreas de concentração, contabilidade geral corresponde ao maior foco das revistas, sendo também destaques aquelas que tratam de aspectos ligados a auditoria e custos/ contabilidade gerencial.

\section{REVISTAS INDEXADAS}

O instituto para informação científica (ISI, Institute for Scientific Information http://www. usinet.com) mantém os índices da ciência que registra todas as citações de artigos científicos apresentados a partir de 1962 em estudos apresentados em revistas especializadas em diversos campos e que estão indexadas. As revistas indexadas são as publicações 
cadastradas no ISI com base em critérios de regularidade de edição, de rigor na avaliação de artigos e de independência de seu conselho editorial. Para efeito de curiosidade, existem apenas dezesseis revistas brasileiras entre as 5.722 de todo o mundo. Dentre essas 5.722 publicações, existem apenas cinco publicações que são específicas sobre contabilidade, sendo quatro dos Estados Unidos e uma do Reino Unido. As revistas de Contabilidade cadastradas no ISI são as seguintes: Accounting Review, Journal of Accounting Research, Journal of Accounting and Economics, Auditing: a Journal of Practice \& Theorye Accounting, Organizations and Society.

\section{REVISTAS ON-LINE}

Como pode ser observado pelo leitor, conforme o endereço expresso na tabela 1, muitas revistas podem ser acessadas, impressas ou lidas pela Internet. Contudo, a grande maioria dessas publicações requer pagamento de assinatura e senha específica para o direito de acesso. Em algumas, pode-se fazer pesquisas gratuitas ou ler os resumos (abstracts), contudo, sem acesso ao texto integral. Outras disponibilizam esporadicamente a última edição ou permitem acesso gratuito por um ou dois meses mediante o cadastramento do usuário. Dentre as publicações deste estudo, algumas podem ser lidas gratuitamente na Internet. Tais revistas são aquelas sublinhadas na tabela 1 , ou seja as de números 3,4 , $39,43,44,52,59,69,98,101$ e 115 . Vale ressaltar que, no momento da pesquisa, essas revistas ofereciam acesso totalmente livre, contudo, evidentemente, mudanças e restrições podem ocorrer no futuro, bem como o acesso a outras revistas pode ser ampliado. Esclarecemos também que o endereço eletrônico de uma publicação específica eventualmente pode mudar. Neste caso, aconselhamos o leitor a fazer uma nova pesquisa na Internet nos endereços acima ou através do endereço http://www. metacrawler.com.

\section{RECOMENDAÇÕES AOS PESQUISADORES}

Recomendações aos autores que buscam veículos tais como os analisados nesta pesquisa:

\section{Definição do seu trabalho propriamente dito}

É vital para o início de trabalho. Consiste na definição de que público-alvo está sendo visado, quais os objetivos da publicação do ponto de vista do autor. Como consequêencia de uma definição clara, torna-se possível a percepção de qual revista é adequada aos objetivos do pesquisador.

\section{Identificação de revistas que potencialmente poderiam aceitar o trabalho}

A identificação das revistas mais adequadas para o tipo de publicação que está sendo pretendida é o próximo passo. Nesse caso, mais de um veículo pode ser identificado; contudo, a ética da publicação considera que não se envie um mesmo trabalho para mais de uma organização, no mesmo momento (vide Borkowski, 1998).

\section{Contato com a revista para identificar os guide lines}

Cada revista tem peculiaridades em termos de formatação, número de páginas, cópias enviadas, rigor de seqüenciamento, citação de autores e obras etc. A maior parte delas segue razoavelmente as normas do Chicago Manual of Style. Esse tipo de postura deve proporcionar condições de evitar muitos desgastes na submissão de trabalhos.

\section{Conceito de artigo inédito}

A revista deve ser consultada no caso de o artigo já ter sido publicado nos anais de algum congresso. $O$ que se sabe é que, normalmente, a publicação apenas do abstract não retira a característica de ineditismo do trabalho.

\section{CONCLUSÃO}

Este trabalho não foi dedicado à identificação de ranking ou mesmo qualificação das revistas acadêmicas que possam trazer contribuições aos estudiosos brasileiros, bem como servir de veículos para suas publicações. $O$ item 4 pretendeu mostrar que existe espaço para publicações, tanto em termos da abertura de um grande número de revistas, como pela frequência de publicação e mesmo disponibilidade de espaço para as várias áreas tratadas. Talvez seja interessante observar, não como crítica, mas como reflexão, que poucos foram os artigos de pesquisadores brasileiros encontrados nos últimos dois anos. Por outro lado, encontramos artigos em revistas americanas e européias, de acadêmicos de 
outros países, notadamente menores e com menos expressão acadêmica do que o Brasil, e cuja primeira língua também não é o inglês. Como se vê, o tema é amplo, importante e merece por parte da comunidade acadêmica mais atenção do que tem recebido a fim de que se aumente/aperfeiçoe, não apenas o número, mas também a qualidade dos trabalhos dos estudiosos brasileiros. A perspectiva de um esforço coletivo, e não apenas isolado, passa pela maior agressividade no acesso a publicações em veículos internacionais não só como leitores passivos, mas também como partícipes da melhoria e da divulgação internacional da pesquisa em contabilidade, principalmente aquela que é feita no Brasil. Nesse sentido, acreditamos firmemente que existem inúmeros pesquisadores em nosso país com potencial suficiente e que podem colaborar com tal desenvolvimento. Finalmente, vale lembrar uma frase famosa que os pesquisadores e cientistas gostam muito de repetir como norma ou advertência e que, talvez, nós acadêmicos da contabilidade tenhamos que aprender: publish or perish...

\section{BIBLIOGRAFIA}

BALL, Ray. WATTS, Ross L. ZIMMERMAN, Jerold L. Editorial: Five year report on the Journal of Accounting and Economics. Journal of Accounting \& Economics, v23n1, May 1997, p. 3-6.

BEATTIE, Vivien A. RYAN, Robert J. The Impact of NonSerial Publications on Research in Accounting and Finance. Abacus, v27n1, Mar 1991, p. 32-50.

BORKOWSKI, Susan C. WELSH, Mary Jeanne. Ethics and accounting publishing process: Author, reviewer, and editor issues. Journal of Business Ethics, v17n16, Dec 1998, p. 1785-1803.

BRICKER, Robert. An Empirical Investigation of the Structure of Accounting Research. Joumal of Accounting Research. v27n2, Autumn 1989, 246-262.

BROWN, Lawrence D. Influential accounting articles, individuals, Ph.D. granting institutions and faculties. A citational analysis. Accounting, Organizations \& Society, v21n7,8, Oct/Nov 1996, p. 723-754.

BRONN, Tony Jones, MICHAEL, John PENDLEBURY, Maurice. UK accountants' $U$ academic accounting journals, 1980 through 1993 Accounting Horizons, v10n1, Mar 1996, p. 1-17.

CHALLIES, Veronica. Infoserve - Information at the Fingertips Accountants' Journal, v72n7, Aug 1993, p. 26-27.

CHANDY, P. R. GANESH, G. K. HENDERSON, G. V. Awareness and Evaluation of Selected Accounting
Journals Inside and Outside the Discipline: An Empirical Study. Akron Business \& Economic Review, v22n2, Summer, p. 214-226,

CORRADO, Charles J. FERRIS, Stephen P. Journal influence on the design of finance doctoral education. Journal of Finance, v52n5, Dec 1997, p. 2091-2102.

CRONIN, Blaise MCKENZIE, Gail, RUBIO, Lourdes WEAVER-WOZNIAK, Sherrill. Accounting for influence: Acknowledgments in contemporary sociology. Journal of the American Society for Information Science, v44n7, Aug 1993, p. 406-412,

ENGLEBRECHT, Ted D. IYER, Govind S. PATTERSON, Denise M. An empirical investigation of the publication productivity of promoted accounting faculty. Accounting Horizons, v8n1, Mar 1994, p. 45- 68.

HUBBARD, Raymond. VETTER, Daniel E. An empirical comparison of published replication research in accounting, finance, management, and marketing. Journal of Business Research, v35n2, Feb 1996, p. 153-164

HULL, Rita P. WRIGHT, Gail B. Faculty Perceptions of Journal Quality: An Update. Accounting Horizons, v4n1, Mar 1990, p. 77-98.

JONES, , M J BRINN, T. PENDLEBURY, M. Judging the quality of research in business schools: A comment from accounting. Omega, v24n5, Oct 1996 , p. $597-602$. 
LEISENRING, James J. JOHNSON, L. Todd. Accounting research: On the relevance of research to Practice. Accounting Horizons, v8 n4 74-79, Dec 1994.

LUKKA, Kari KASANEN, Eero. Is accounting a global or a local discipline? Evidence from major research journals. Accounting, Organizations \& Society, v21n7,8, Oct/Nov 1996, p. 755-773.

McNULTY, James E BOEKELOO, John. Two approaches to measuring journal quality: Application to finance journal. Journal of Economics \& Finance, v23n1, Spring 1999, p. 30-38.

MILLS, Patti A. Accounting history as social science: A cautionary Note. Accounting, Organizations \& Society, v18n7,8, Oct/Nov 1993, p. 801-803.

O'DONOHOE, S. DIAMANTOPOLUOS, A. PETERSEN, N. Marketing Principles and Practice in the Accounting Profession: A Review European Journal of Marketing, v25n6, 1991, p. 37-54,
SMITH, Katherine T SMITH, L. M. Use of professional journal ads to promote accounting services. Journal of Professional Services Marketing, v17n2, 1998, p. 109-116.

TAHAI, Alireza MEYER, Michael J. A revealed preference study of management journals' direct influences. Strategic Management Journal, v20n3, Mar 1999, p. $279-296$.

TAHAI, Alireza RIGSBY, JohnT. Information processing using citations to investigate journal influence in accounting. information Processing \& Management, v34n2,3, Mar/ May 1998 , p. $341-359$.

URBANIC, Frank R. Measuring the Eminence of Business Schools: A Longitudinal Analysis. Akron Business \& Economic Review, v20n3, Fall 1989, p. 29-39.

ZEFF, Stephen A. A study of academic research journals in accounting. Accounting Horizons. v10n3, Sep 1996, p. $158-177$. 


\section{RELAÇÃO DAS REVISTAS ANALISADAS, PAÍS ONDE SÃO PUBLICADAS, INSTITUIÇÃO RESPONSÁVEL E ENDEREÇO}

NOME DA REVISTA Accounting, Finance, and Business Studies

2. Academy of Accounting and Financial Studies Journal
1. Abacus: A Journal of

\section{PAIS PUBLICADO/EDITADO}

Austrália Department of Accounting University of Sidney

EUA Western Carolina University Brigham Young University

\section{ENDEREÇO ELETRÔNICO}

http://Www.blackwellpublishers.co.uk ou http:/ /Www.blackwellpublishers.co.uk/asp/ journal.asp?ref $=0001-3072$

http://Www.alliedacademies.org/accounting/ index.html

htttp://www.accoutancymag.co.uk Accountants in England and Wales (ICAEW)

4. Accountancy Ireland

Rep.Irlanda Institute of Chartered

http://WwW.icai.ie/Accountancy-Ireland/

Accountants in Ireland

\begin{tabular}{llll}
\hline 5. Accountant (The) & Reino Unido & Lafferty Publications Ltd & www.lafferty.co.uk \\
\hline 6. Accounting \& Business & Reino Unido & $\begin{array}{l}\text { Association of Chartered } \\
\text { Certifield Accountants }\end{array}$ & prmedia@email.msn.com \\
\hline
\end{tabular}

7. Accounting and Business Research

Reino Unido Institute of Chartered Accountants in England and Wales (ICAEW)

8. Accounting and Business Review Cingapura Nanyang Technological University - Singapore

9. Accounting and Finance Reino Unido Austrália e Nova Zelânida Blackwell Publishers

\begin{tabular}{|c|c|c|c|}
\hline $\begin{array}{l}\text { 10. Accounting and Public } \\
\text { Interest }\end{array}$ & EUA & $\begin{array}{l}\text { American Accounting } \\
\text { Association, Public Interest } \\
\text { Section } \\
\text { University of New Mexico }\end{array}$ & $\begin{array}{l}\text { http://www.rutgers.edu/Accounting/raw/aaa/ } \\
\mathrm{pi} / \text { journal/author.instructions.html }\end{array}$ \\
\hline $\begin{array}{l}\text { 11. Accounting Business and } \\
\text { Financial History }\end{array}$ & Reino Unido & $\begin{array}{l}\text { Routledge } \\
\text { Cardiff Business School }\end{array}$ & $\begin{array}{l}\text { http://Www.routledge.com ou } \\
\text { http://Www.tandf.co.uk/journals/routledge/ } \\
\text { 09585206.html }\end{array}$ \\
\hline $\begin{array}{l}\text { 12. Accounting Education: A } \\
\text { Journal of Theory, Practice } \\
\text { \& Research }\end{array}$ & EUA & $\begin{array}{l}\text { Jai Press Ltd. } \\
\text { Villanova University, Virginia } \\
\text { Commowealth University }\end{array}$ & http://Www.nan.shh.fi/anet//ists/aaatc-l/0005.html \\
\hline $\begin{array}{l}\text { 13. Accounting Education: A } \\
\text { International Journal }\end{array}$ & Reino Unido & $\begin{array}{l}\text { Chapman \& Hall } \\
\text { Loughborough University }\end{array}$ & $\begin{array}{l}\text { http://www.tandf.co.uk/journals/routledge/ } \\
\text { 09639284.html }\end{array}$ \\
\hline $\begin{array}{l}\text { 14. Accounting Educators } \\
\text { Journal (the) }\end{array}$ & EUA & University of Idaho & http://www.uidaho.edu/cbe/aej/journal.html \\
\hline 15. Accounting Enquires & Canadá & Stanversal Publishing & $\begin{array}{l}\text { Scarborough, Ontario, Canada } \\
\text { P.O Box } 37352\end{array}$ \\
\hline
\end{tabular}

http://www.accountancymag.co.uk

http://www.wspc.com.sg/journals/abr/abr.html

http://www.blackwellpublishers.co.uk P.O Box 37352
Accounting Association of
Reino Unido
Blackwell Publishers. University
Of South Austrália.
16. Accounting Forum
www.blackwellpublishers.co.uk
17. Accounting Historians EUA School of Accounting - Journal (The) University of Alabama

http://weatherhead.cwru.edu/Accounting/pub/ journal.html 
TABELA 1 (continuação)

NOME DA REVISTA

PAís

PUBLICADO/EDITADO

ENDEREÇO ELETRÔNICO

18. Accounting Horizons

EUA American Accounting

Association (AAA)

http://www.rutgers.edu/Accouting/raw/aaa/ pub/

\begin{tabular}{|c|c|c|c|}
\hline $\begin{array}{l}\text { 19. Accounting } \\
\text { Journal }\end{array}$ & Austrália & $\begin{array}{l}\text { School of Economics and } \\
\text { Finance - Royal Melbourne } \\
\text { Institute of Technology }\end{array}$ & http://www.bf.rmit.edu.au/econfin/.arj.html \\
\hline 20. Accounting Review (The) & EUA & $\begin{array}{l}\text { American Accounting } \\
\text { Association (AAA) }\end{array}$ & $\begin{array}{l}\text { http://www.rutgers.edu/Accouting/raw/aaa/ } \\
\text { pub/ }\end{array}$ \\
\hline
\end{tabular}

21. Accounting Technology (Ex

EUA Faulkner \& Gray

http://www.faulknergray.com/ists/actech.htm
EUA Faulkner \& Gray

22. Accounting Today

23. Accounting, Auditing \& Accountability Journal

24. Accounting, Management and Information Technologies

25. Accounting, Organizations and Society

\section{Reino Unido}

Eselvier Science

University of Oxford

London School of Economics

and Political Science

26. Advances in Accounting

EUA

Jai Press Ltd

Arizona State University

27. Advances in Accounting

Behavioral Research

EUA Jai Press Ltd

University of South Florida

EUA Jai Press Ltd

Virginia Commowealth

University, Villanova University

Educational Teaching and

Curriculum Innovations

29. Advances in Accounting Information Systems

EUA Jai Press Ltd

Texas Tech University

30. Advances in Environmental Accounting and Management

EUA

Jai Press Ltd

New York State University

Rutgers University

31. Advances in International Accounting

32. Advances in Management Accounting

EUA Jai Press Ltd University of Cincinnati

\section{EUA Jai Press Ltd}

Rice University

Insead

33. Advances in Public Interest Accounting

EUA

Jai Press Ltd

Hofstra University

34. Advances in Quantitative Analysis of Finance and Accounting

EUA Jai Press Ltd

Rutgers University
http://www.numen-lumen.com/MgR/ AccountingToday.html

http://mcb.co.uk/aaaj.htm

http://Www.elsevier.nl//ocate/amit ou http://weatherhead.cwru.edu/amit/

http://www.elsevier.nl/inca/publications/store/ $4 / 8 / 6 /$

http://www.jaipress.com/Accounting

http://www.jaipress.com/Accounting

http://www.jaipress.com/Accounting

http://www.jaipress.com/Accounting

http://www.jaipress.com/Accounting

http://Www.jaipress.com/Accounting

http://www.jaipress.com/Accounting

http://www.jaipress.com/Accounting

http://www.jaipress.com/Accounting 
TABELA 1 (continuação)

NOME DA REVISTA

35. Advances in Taxation

36. Asia Review of Accounting Austrália

Australia

Curtin University of Technolog

Hong Kong Polytechnic

University, Victoria University of

Technology

\begin{tabular}{|c|c|c|c|}
\hline 37. Auditing, Litigation and Tax & EUA & $\begin{array}{l}\text { Social Science Electronic } \\
\text { Publishing } \\
\text { Rochester University }\end{array}$ & $\begin{array}{l}\mathrm{http}: / / w w w . s s \mathrm{w} \text {.com/update/arn/ } \\
\text { arn_auditlit.html }\end{array}$ \\
\hline
\end{tabular}

\begin{tabular}{|c|c|c|c|}
\hline $\begin{array}{l}\text { 38. Auditing: A Journal of } \\
\text { Practice \& Theory }\end{array}$ & EUA & $\begin{array}{l}\text { American Accounting } \\
\text { Association - Auditing Sector } \\
\text { Boston College }\end{array}$ & $\begin{array}{l}\text { http://www.rutgers.edu/Accouting/raw/aaa/ } \\
\text { pub/ }\end{array}$ \\
\hline $\begin{array}{l}\text { 39. Australian Accounting } \\
\text { Review }\end{array}$ & Austrália & $\begin{array}{l}\text { Australian Society of CPAs } \\
\text { University of Sidney }\end{array}$ & http://cpaonline.com.au/library/fs_aar.htm \\
\hline 40. Australian CPA & Austrália & Australian Society of CPAs & $\begin{array}{l}\text { http://www.cpaonline.com.au/library/ } \\
\text { pg_aa_index } 98 . h t m\end{array}$ \\
\hline
\end{tabular}

\begin{tabular}{lll}
\hline 41. Behavioral Research in EUA & Behavior and Organizations http://www.rutgers.edu/Accouting/raw/aaa/ \\
Accounting & Section da American Accounting pub/ \\
& Association \\
& Lousiana State University
\end{tabular}

\begin{tabular}{lcll}
\hline 42. British Accounting Review & Reino Unido & British Accounting Association & http://www.academicpress.com/bar \\
\hline $\begin{array}{l}\text { 43. Business Finance (Ex } \\
\text { Controller Magazine) }\end{array}$ & EUA & $\begin{array}{l}\text { Duke Communications } \\
\text { International }\end{array}$ & $\mathrm{http} / /$ www.businessfinancemag.com/ \\
\hline
\end{tabular}

\begin{tabular}{|c|c|c|c|}
\hline 44. CA Magazine & Canadá & $\begin{array}{l}\text { The Canadian Institute of } \\
\text { Chartered Accountants }\end{array}$ & $\begin{array}{l}\text { http://Www.cica.ca/ ou } \\
\text { http://accounting.about.com/jobs/accounting/ } \\
\text { gi/dynamic/offsite.htm?site=http://Www.cica.ca/ } \\
\text { cica/camagazine.nsf/eCurrent/toc }\end{array}$ \\
\hline
\end{tabular}

\begin{tabular}{|c|c|c|c|}
\hline 45. CGA Magazine & Canadá & $\begin{array}{l}\text { Certifield General Accountants } \\
\text { Association of Canada }\end{array}$ & www.cga-canada.org \\
\hline 46. Chartered Accountant (The) & India & $\begin{array}{l}\text { Institute of Chartered } \\
\text { Accountants of India }\end{array}$ & www.icai.org \\
\hline $\begin{array}{l}\text { 47. China Accounting and } \\
\text { Finance Review }\end{array}$ & China & $\begin{array}{l}\text { Hong Kong Polytechnic } \\
\text { University e Tsinghua University }\end{array}$ & $\begin{array}{l}\text { acswan@inet.polyu.edu.hk } \\
\text { (852) } 27667046\end{array}$ \\
\hline $\begin{array}{l}\text { 48. CMA Canada Management } \\
\text { (EX CMA Magazine) }\end{array}$ & Canadá & CMA - Canada & Www.managementmag.com \\
\hline $\begin{array}{l}\text { 49. Contemporary Accounting } \\
\text { Research }\end{array}$ & Canadá & $\begin{array}{l}\text { Canadian Academic Accounting } \\
\text { Association } \\
\text { University of British Columbia }\end{array}$ & http://www.caaa.ca \\
\hline 50. Cost Engineering & EUA & $\begin{array}{l}\text { Association for Advancement of } \\
\text { cost Engineering though total } \\
\text { cost Management }\end{array}$ & $\begin{array}{l}\text { http://www.aacei.org/newdesign/library/ } \\
\text { welcome.shtml }\end{array}$ \\
\hline 51. CPA Journal (The) & EUA & $\begin{array}{l}\text { The New York State Society of } \\
\text { Certifield Public Accountants }\end{array}$ & cpaj@luca.com \\
\hline
\end{tabular}

Caderno de Estudos, São Paulo, FIPECAFI, v.13, n. 24, p. 50 - 78, julho/dezembro 2000 
NOME DA REVISTA

PAís PUBLICADO/EDITADO

ENDEREÇO ELETRÔNICO

52. CPA Letter

EUA AICPA - American Institute of

www.aicpa.org

Certifield Public Accountants

\begin{tabular}{llll}
$\begin{array}{l}\text { 53. Critical Perspectives in } \\
\text { Accounting }\end{array}$ & Canadá & $\begin{array}{l}\text { Academic Press } \\
\text { University of Alberta } \\
\text { City University of New York }\end{array}$ & $\begin{array}{l}\text { http://www.academicpress.com/cpa ou } \\
\text { http://www.apnet.com/cpa }\end{array}$ \\
\hline 54. EDPACS & EUA & CRC Press LLC & $\begin{array}{l}\text { http://www.auerbach-publications.com/ } \\
\text { catalog/edpc.htm }\end{array}$ \\
\hline
\end{tabular}

55. Education: An International Reino Unido Routledge http://www.routledge.com Journal

\begin{tabular}{|c|c|c|c|}
\hline $\begin{array}{l}\text { 56. European Accounting } \\
\text { Review(The) }\end{array}$ & Reino Unido & $\begin{array}{l}\text { Routledge } \\
\text { European Accounting } \\
\text { Association }\end{array}$ & stichtenoth@eiasm.be \\
\hline $\begin{array}{l}\text { 57. Financial Accountability and } \\
\text { Management }\end{array}$ & Reino Unido & $\begin{array}{l}\text { Blackwell Publishers } \\
\text { University of Edinburgh }\end{array}$ & http://www.blacwellpublishers.co.uk \\
\hline $\begin{array}{l}\text { 58. Government Accountants } \\
\text { Journal (The) }\end{array}$ & EUA & $\begin{array}{l}\text { Association of Government } \\
\text { Accountants }\end{array}$ & srosner@agacgfm.org \\
\hline 59. IFAC Quarterly & EUA & $\begin{array}{l}\text { IFAC International Federation of } \\
\text { Accountants- }\end{array}$ & http://www.ifac.org/ \\
\hline $\begin{array}{l}\text { 60. Information Systems } \\
\text { Control Journal }\end{array}$ & Austrália & $\begin{array}{l}\text { Information System Audit and } \\
\text { Control Association }\end{array}$ & http://www.isaca.org/jrnlhorme.htm \\
\hline 61. Internal Auditing & EUA & $\begin{array}{l}\text { Warrem. Gorham \& Lamont/Ria } \\
\text { Group }\end{array}$ & Fone $(800) 950-1205$ \\
\hline 62. Internal Auditor & EUA & Institute of Internal Auditors & http://www.theiia. org/period/ia.htm \\
\hline $\begin{array}{l}\text { 63. International Journal of } \\
\text { Accounting (The) }\end{array}$ & EUA & $\begin{array}{l}\text { JAI Press } \\
\text { University of Illinois at Urbana- } \\
\text { Champaign }\end{array}$ & $\begin{array}{l}\text { http://www.cpaonline.com.au/library/ } \\
\text { pg_aa_index98.htm }\end{array}$ \\
\hline $\begin{array}{l}\text { 64. International Journal of } \\
\text { Government Auditing }\end{array}$ & EUA & U.S. General Accounting Office & chases@gao.gov \\
\hline $\begin{array}{l}\text { 65. International Journal of } \\
\text { Intelligent Systems in } \\
\text { Accounting, Finance \& } \\
\text { Management }\end{array}$ & EUA & $\begin{array}{l}\text { John Wiley \& Sons, Ltd } \\
\text { University of South California }\end{array}$ & http://www.interscience.wiley.com \\
\hline
\end{tabular}

66. Irish Accounting Review

Rep. Irlanda Irish Accounting and Finance

Htttp:/WwW.oaktreepress.com

Association

University of Ulster

National University of Ireland

\begin{tabular}{lll}
\hline $\begin{array}{l}\text { 67. Issues in Accounting } \\
\text { Education }\end{array}$ & EUA & $\begin{array}{l}\text { American Accounting } \\
\text { Association (AAA) } \\
\text { College of Willian \& Mary }\end{array}$ \\
\hline
\end{tabular}

68. Journal of International

EUA WG \& C - RIA

http://Www.riatax.com/journals/joit/joitfred.html Taxation 
NOME DA REVISTA

69. Journal of Accountancy
PAís

PUBLICADO/EDITADO

EUA

EUA

Elsevier Science

University of Rochester

Economics

71. Journal of Accounting and Business Society

72. Journal of Accounting and Public Policy

73. Journal of Accounting Case Canadá Research

\begin{tabular}{l} 
74. Journal of Accounting \\
Education \\
\hline $\begin{array}{l}\text { 75. Journal of Accounting } \\
\text { Information System }\end{array}$ \\
$\begin{array}{l}\text { 76. Journal of Accounting } \\
\text { Literature }\end{array}$ \\
$\begin{array}{l}\text { 77. Journal of Accounting } \\
\text { Research }\end{array}$
\end{tabular}

78. Journal of Accounting, Auditing, \& Finance

79. Journal of American Taxation Association (The)

EUA

EUA

EUA

AICPA - American Institute of Certifield Public Accountants

www.aicpa.org ou

http://accounting.about.com/jobs/accounting/ gi/dynamic/offsite.htm? site $=$ http:// www.aicpa.org/pubs/jofa/joaiss.htm

http://elsevier.com/locate/econbase

Malangkucecwara College of Economics, INA

http://www.nan.shh.fi/anet/lists/asocial-l/ 0130.html

EUA Elsevier Science Www.elsevier.com/locate/jaccpubpol University of Maryland

Captus Press Inc.

University of Lethbridge

http://www.captus.com

Elsevier Science James Madison University

http://www.elsevier.com/inca/publications

Pergamon

Texas Tech University

http://www.elsevier.com/inca/publications/ store $/ 6 / 2 / 0 / 4 / 0 / 0 /$

EUA $\quad$ Fisher School of Accounting University of Florida

EUA Institute of Professional Accounting - Graduate School of Business - University of Chicago

http://www.cba.ufl.edu/FSOA/shoolinfo/jal.html http://www.gsbwww.uchicago.edu/research/ journals/jar

$\begin{array}{ll}\text { EUA } & \text { Institute of Accounting Research http://www.grewood.com.jaaf.htm } \\ & - \text { New York University }\end{array}$

$\begin{array}{ll}\text { EUA } & \text { Institute of Accounting Research http://www.grewood.com.jaaf.htm } \\ & - \text { New York University }\end{array}$ American Taxation Association - http://www.rutgers.edu/Accouting/raw/aaa/pub/ American Accounting Association

\begin{tabular}{|c|c|c|c|}
\hline $\begin{array}{l}\text { 80. Journal of Applied } \\
\text { Accounting Research }\end{array}$ & Reino Unido & $\begin{array}{l}\text { Leigh Holland } \\
\text { De Monfforte University }\end{array}$ & $\begin{array}{l}\text { http://www.publist.com/cgi-bin/ } \\
\text { show?PLID=4832747 }\end{array}$ \\
\hline $\begin{array}{l}\text { 81. Journal of Bank Cost \& } \\
\text { Management }\end{array}$ & EUA & $\begin{array}{l}\text { National Association for Bank } \\
\text { Cost \& Management Accounting }\end{array}$ & http://www.amifs. org/journal.shtml \\
\hline $\begin{array}{l}\text { 82. Journal of Business Finance } \\
\text { \& Accounting }\end{array}$ & Reino Unido & $\begin{array}{l}\text { Blackwell Publishers } \\
\text { University of Hull }\end{array}$ & htttp://www.blackwellpublishers.co.uk \\
\hline $\begin{array}{l}\text { 83. Journal of Corporate } \\
\text { Accounting \& Finance (The) }\end{array}$ & EUA & John Wiley \& Sons, Inc. & JCAFmail@juno.com \\
\hline 84. Journal of Cost Analysis & EUA & $\begin{array}{l}\text { Scea National Office } \\
\text { Society of Cost Estimating \& } \\
\text { Analysis }\end{array}$ & http://www.erols.com/scea \\
\hline $\begin{array}{l}\text { 85. Journal of Cost } \\
\text { Management }\end{array}$ & EUA & Warren, Gorham \& Lamont & tpowelll@riag.com \\
\hline $\begin{array}{l}\text { 86. Journal of Financial } \\
\text { Statement Analysis }\end{array}$ & EUA & $\begin{array}{l}\text { Institution Investor, Inc. } \\
\text { New York University }\end{array}$ & $\begin{array}{l}\text { http://www.stern.nyu.edu/acc/journals/ } \\
\text { jfsa2.html }\end{array}$ \\
\hline
\end{tabular}


NOME DA REVISTA

PAís

PUBLICADO/EDITADO

ENDEREÇO ELETRÔNICO

87. Journal of Forensic Accounting, Audit, Fraud

and Taxation

88. Journal of Information System

EUA American Accounting

Asscociation - Information

Systems Section - Georgia

State University

89. Journal of International

Accounting, Auditing e

EUA

JAI Press

Western Michigan University

Taxation

90. Journal of International

Financial Management and

Reino Unido Blakewell Publishers Ltd

New York University

Accounting

91. Journal of Management

Accounting Research

EUA

Management Accounting

http://aaa-mas.byu.edu/jmar/jmarhome.htm

Section - American Accounting

Association (AAA)

University of Waterloo

92. Journal of Public Budgeting
Accounting \& Financial

EUA PrAcademic Press

University of Tulsa

Florida Atlantic University

Pennsylvania State University

Lousiana State University

93. Journal of Taxation

EUA

WG \& C - RIA

EUA WG \& C - RIA

94. Journal of Taxation of

Exempt Organizations

95. Management Accountant India

95. Management Accountant

Institute of Cost and Works

Accountants in India

96. Management Accountant

Paquistão

Institute of Cost and

Management Accountants

of Pakistan

97. Management Accounting -
London

Reino Unido

Chartered Institute of

Management Accountants

EUA

Institute of Management

Accountants - IMA
http://www.rtedwards.com/journals/JFA

http://www.rutgers.edu/Accouting/raw/aaa/pub/

http://Www.jaipress.com/Accounting

jnlinfo@blacwellpublishers.co.uk

k

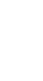

(


NOME DA REVISTA

PAís

PUBLICADO/EDITADO

ENDEREÇO ELETRÔNICO

102. National Tax Journal

EUA National Tax Association Syracuse University

103. New Accountant

EUA

Real State News Corp.

104. Pacific Accounting Review

Nova Zelândia Department of Accountancy Massey University

105. Petroleum Accounting and Financial Management Journal

\begin{tabular}{|c|c|c|c|}
\hline 106. Practical Accountant & EUA & Faulkener \& Gray & http://www.faulknergray.com/account/prac.htm \\
\hline 107. Practical Tax Strategies & EUA & WG \& L - RIA & http://www.riatax.com/journals/eotj/eotjsub.html \\
\hline $\begin{array}{l}\text { 108. Research in Accounting } \\
\text { Ethics }\end{array}$ & Reino Unido & $\begin{array}{l}\text { Jai Press Ltd } \\
\text { Price Waterhouse } \\
\text { Rice University } \\
\text { State University of New York }\end{array}$ & http://www.jaipress.com/Accounting \\
\hline $\begin{array}{l}\text { 109. Research in Accounting in } \\
\text { Emerging Economies }\end{array}$ & Reino Unido & $\begin{array}{l}\text { Jai Press Ltd } \\
\text { King Fahad University of Petroleum } \\
\text { e Minerals - Arábia Saudita }\end{array}$ & http://www.jaipress.com/Accounting \\
\hline $\begin{array}{l}\text { 110. Research in Accounting } \\
\text { Regulation }\end{array}$ & Reino Unido & $\begin{array}{l}\text { Jai Press Ltd } \\
\text { Case Western Reserve University }\end{array}$ & http://Www.jaipress.com/Accounting \\
\hline $\begin{array}{l}\text { 111. Review of Accounting } \\
\text { Information Systems }\end{array}$ & EUA & $\begin{array}{l}\text { Western Academic Press } \\
\text { Metropolitan State College of } \\
\text { Denver }\end{array}$ & http:/Www.wapress.com/jabr/index..html \\
\hline $\begin{array}{l}\text { 112. Review of Accounting } \\
\text { Studies }\end{array}$ & EUA & $\begin{array}{l}\text { Kluwer Academic Publishers } \\
\text { University of Pennsylvania, } \\
\text { Cornell University, University of } \\
\text { California, University of } \\
\text { Michigan, Columbia University }\end{array}$ & $\begin{array}{l}\text { dthelp@wkap.com } \\
\text { http://www.haas.berkeley.edu/groups/rast/ }\end{array}$ \\
\hline $\begin{array}{l}\text { 113. Review of Quantitative } \\
\text { Finance and Accounting }\end{array}$ & EUA & $\begin{array}{l}\text { Kluwer Academic Publishers } \\
\text { Rutgers University }\end{array}$ & $\begin{array}{l}\text { http://www.wkap.nl/jou rnalhome.htm/0924- } \\
865 \text { X ou http://www.kluweronline.nl }\end{array}$ \\
\hline 114. Singapore Accountant & Cingapura & Longman Singapore Publishers & $\begin{array}{l}\text { http://www.publist.com/cgi-bin/ } \\
\text { show?PLID=3827422 }\end{array}$ \\
\hline $\begin{array}{l}\text { 115. Strategic Finance (Ex } \\
\text { Management Accounting - } \\
\underline{\text { USA) }}\end{array}$ & EUA & $\begin{array}{l}\text { Institute of Management } \\
\text { Accountants (IMA) }\end{array}$ & http://www.strategicfinancemag.com \\
\hline $\begin{array}{l}\text { 116. Studies in Managerial and } \\
\text { Financial Accounting }\end{array}$ & EUA & $\begin{array}{l}\text { Jai Press Ltd } \\
\text { Long Island University }\end{array}$ & http://Www.jaipress.com/Accounting \\
\hline $\begin{array}{l}\text { 117. Studies in the } \\
\text { Development of Accounting } \\
\text { thought }\end{array}$ & EUA & $\begin{array}{l}\text { Jai Press Ltd } \\
\text { Case Western University }\end{array}$ & http:/Www.jaipress.com/Accounting \\
\hline
\end{tabular}

118. Valuation

EUA
EUA Institute of Petroleum Accounting www.unt.edu/ipa

- University of North Texas
(773) $866-9900 /(773) 866-9907$

http://Mww.ntanet.org/national_tax_journal.htm

http://www.mngt.waikato.ac.nz/par International Board of Govemors 


\section{TABELA 2}

\section{ÁREA DE INTERESSE EXPRESSA NOS EDITORIAIS DAS REVISTAS OU COMPREENDIDA PELOS AUTORES E ENFOQUE}

1. Abacus: A Journal of Accounting, Finance, and Business Studies
Artigos que expõem uma visão exploratória, crítica e construtiva de todos os aspectos contábeis e/ou artigos nos quais a teoria das organizações e do comportamento econômico são usualmente relacionadas com a contabilidade, as finanças e negócios
2. Academy of Accounting and Financial Studies Journal
Todos os aspectos relacionados com a contabilidade e finanças. Difícil de definir uma área específica, mesmo porque o editorial não a menciona
Internacional

Internacional

\begin{tabular}{llll}
\hline 3. Accountancy & Aspectos da auditoria e da contabilidade numa perspectiva profissional & Local \\
\hline 4. Accountancy Ireland & $\begin{array}{l}\text { Notícias e análises da profissão contábil na Irlanda focada para os contadores } \\
\text { certificados }\end{array}$ & Local \\
\hline 5. Accountant (The) & Informativo sobre aspectos gerais da contabilidade e auditoria & Local \\
\hline 6. Accounting \& Business & Aspectos gerais sobre contabilidade e negócios & Local
\end{tabular}

7. Accounting and Business Conteúdo analítico e/ou empírico, preferencialmente inteligíveis para um Internacional Research amplo grupo de acadêmicos e profissionais. Faz resenha de livros

8. Accounting and Business Review

Aspectos gerais sobre contabilidade para acadêmicos e Internacional profissionais.Focaliza, principalmente, análise financeira, economia, cigarros e sistemas de informação

9. Accounting and Finance Artigos teóricos e empíricos que tenham alguma relação com a contabilidade, finanças e economia - estudos de caso, pesquisas de campo e análise histórica.

10. Accounting and Public Interest
Nova revista da AAA-American Accounting Association que focaliza as descobertas e as relações do interesse público situado dentro do contexto político, ético, social e econômico. Pretende promover um guia para a ação responsável através da contabilidade. Publica também uma newsletter. É o primeiro jornal exclusivamente on-line sobre contabilidade
11. Accounting Business and Financial History
Ressalta as interrelações entre práticas contábeis, mercados financeiros e desenvolvimento econômico. A influência da contabilidade na tomada de decisões e nos sistemas sociais e ambientais. Traz resenha de livros
Local

Internacional

Aspectos pedagógicos, métodos de ensino ou programas de aperfeiçoamento

Local de currículo. Journal of Theory, Practice \& Research

13. Accounting Education: A International Journal

Artigos sobre aspectos chaves da educação (o que ensinamos? e como

Internacional ensinamos?) e treinamento contábil para acadêmicos, estudantes e profissionais.

Meios para os educadores se comunicarem sobre a relevância das descobertas

Local

14. Accounting Educators Journal (the) do processo educacional em contabilidade. Faz resenha de livros

Publica assuntos gerais sobre contabilidade, principalmente, teoria da Internacional

15. Accounting Enquires contabilidade, auditoria, padrões contábeis e história da contabilidade
Artigos em todas as áreas da contabilidade, negócios e finanças - teoria e prática. Procura focalizar o papel dos negócios no mundo globalizado.
Local

16. Accounting Forum

Aspectos do pensamento e da prática contábil relacionados com a história da contabilidade. Ressalta os aspectos da história contábil numa perspectiva contemporânea. Publica também uma newsletter: Accounting Historians Notebook.
17. Accounting Historians Journal (The)
Internacional 
TABELA 2 (continuação)

NOME DA REVSTA

ÁREA RESUMIDA DE ENFOQUE EXPRESSA NO EDITORIAL E/OU COMPREENDIDA
19. Accounting Research Journal
Desenhada primeiramente para divulgar artigos de contabilidade aplicada com intuito de facilitar a compreensão das mais importantes pesquisas cientificas desenvolvidas por estudiosos da contabilidade. Os assuntos devem focalizar tópicos de interesse de educadores, contadores e estudantes de contabilidade procurando fazer uma eficiente comunicação entre os três grupos.
Enfatiza a comunicação entre profissionais e acadêmicos na pesquisa e na prática da contabilidade, finanças, auditoria, leis comerciais e disciplinas correlacionadas. Também publica notas sobre educação e estudos de caso.
ENFOQUE

Internacional

Internaciona

Internacional

Deveria ser vista como a principal revista para publicar artigos relatando os resultados de pesquisas contábeis com forte enfoque na metodologia da pesquisa. Seu âmbito é amplo, publicando quaisquer assuntos relacionados com a contabilidade. É dirigida, principalmente, para acadêmicos, estudantes de pós e outros interessados em pesquisa contábil. Também faz periodicamente resenhas de livros sobre contabilidade.
21. Accounting Technology (Ex Computers in Accounting)

22. Accounting Today
Artigos sobre tecnologia e contabilidade, principalmente aspectos profissionais, impostos, sistemas, softwares e equipamentos. diversas gravações sobre esse temas que podem ser ouvidos em seu site pela Internet

23. Accounting, Auditing \& Accountability Journal
Enfatiza a interação entre a contabilidade e auditoria e os ambientes políticos e sócio-econômicos. Encoraja as análises críticas das políticas e das práticas dessas áreas. Procura explorar as políticas alternativas com intuito de prover novas perspectivas para a disciplina contábil. Traz resenha de livros
Publica os avanços e as interrelações da tecnologia da informação com a contabilidade, os sistemas de controle e as práticas e políticas gerenciais and Information Technologies

25. Accounting, Organizations and Society

Artigos relacionados com o papel social da contabilidade, o comportamento humano, os processos e estruturas organizacionais, e as mudanças no processo político e social das empresas.
Internacional Internacional Temas emergentes em qualquer assunto relacionado com a contabilidade. Enfoca os diversos tipos de metodologias em artigos empíricos e/ou analíticos.

27. Advances in Accounting Behavioral Research

Artigos relacionados com as pesquisas em contabilidade comportamental, como por exemplo, aquelas que enfocam as relações entre o comportamento humano e o processo de tomada de decisão. Áreas da contabilidade que incorporam e se relacionam com a psicologia aplicada, a sociologia, a administração e a economia

Métodos de ensino e/ou avaliação, programas, currículos sobre contabilidade, auditoria e outras áreas dos negócios

Internacional

28. Advances in Accounting Educational Teaching and Curriculum Innovations

29. Advances in Accounting Information Systems

Examina a relação entre contabilidade e tecnologia da informação através Internacional de artigos empíricos e analíticos, baseados na prática ou no desenvolvimento de novas tecnologias

30. Advances in Environmental and Accounting Management

Relaciona o desenvolvimento da contabilidade com as perspectivas da Internacional natureza, seus significados, fundamentos e proposições. Análise da mensuração e do gerenciamento e utilização dos recursos naturais

31. Advances in International Accounting

Artigos que focalizam os aspectos da contabilidade numa perspectiva mundial. Normas internacionais e aspectos específicos da contabilidade em vários países 

EDITORIAL EIOU COMPREENDIDA

32. Advances in Management Accounting

33. Advances in Public Interest Accounting
Publica artigos que focalizam aspectos relacionados com a tomada de decisão, a contabilidade de custos e a contabilidade gerencial.
Internacional

Internacional

A relação entre a contabilidade e o interesse público numa perspectiva que focaliza a transparência das informações e os interesses da sociedade como um todo
34. Advances in Quantitative Analysis of Finance and Accounting
Focaliza diversas abordagens dos métodos quantitativos (contabilometria) aplicados a contabilidade, a auditoria e a finanças
Internacional

action

35. Advances in Taxation

Jornal acadêmico sobre impostos. Focaliza aspectos internacionais, nacionais, estaduais e municipais. É interdisciplinar, envolvendo pesquisas que relacionam os impostos com a economia, as finanças, e o direito.

36. Asia Review of Accounting Assuntos relacionados com a contabilidade, impostos, auditoria e administração financeira de paises da Ásia/Pacifico. Faz resenha de livros.

Internacional Aspectos gerais sobre auditoria, litigio e impostos em corporaçoes americanas

37. Auditing, Litigation and Tax

Aspectos gerais sobre auditoria, litígio e impostos em corporações americanas

Local

Artigos sobre a prática e os aspectos teóricos da auditoria. O termo auditoria

38. Auditing: A Journal of é interpretado amplamente. Publica também uma newsletter. Practice \& Theory

Focaliza a discussão e desenvolvimento da contabilidade na Austrália. Faz uma

Local

39. Australian Accounting Review ponte entre a academia e os negócios publicando artigos e tópicos de ambos.

\begin{tabular}{llll}
\hline 40. Australian CPA & Aspectos gerais sobre contabilidade - dirigida para o CPA australiano & Local \\
\hline $\begin{array}{l}\text { 41. Behavioral Research in } \\
\text { Accounting }\end{array}$ & $\begin{array}{l}\text { Objetiva promover a divulgação dos resultados das pesquisas acadêmicas } \\
\text { dentro de um amplo campo da contabilidade, principalmente aqueles que } \\
\text { focalizam as decisões das pessoas através das informações geradas } \\
\text { pela contabilidade }\end{array}$ \\
\hline
\end{tabular}

42. British Accounting Review

Artigos com características teóricas e empíricas. É uma revista eclética e pluralista que publica diversos temas relacionados com a contabilidade. Faz Internacional resenha de livros.

43. BusinesFinance (Ex Controller Magazine)

Informações gerais sobre contabilidade e finanças para executivos financeiros Local e de contabilidade. Publica também uma newsletter

Focaliza aspectos relacionados com a auditoria, contabilidade e tecnologias

Local

44. CA Magazine relacionadas

45. CGA Magazine

Aspectos gerais da contabilidade e dos negócios relacionados com o Canadá.

Local É bilingüe (inglês e francês)

\section{Chartered Accountant (Th \\ 47. China Accounting and Finance Review}

Aspectos da contabilidade, auditoria e dos negócios relacionados com a Índia.

Local

Publica pesquisas relacionadas com a China sobre contabilidade e finanças empregando todos os tipos de metodologias - analítica, comportamental, conceitual, empírica e experimental. Publica também assuntos relacionados com a educação e estudos de casos. É bilíngüe (inglês e chinês).

48. CMA Canada Management

Publica artigos dirigidos para os CMA - Certifield Management Accountants

Local

49. Contemporary Accounting Research

Publica trabalhos relacionados com todas as áreas da contabilidade. Também focaliza pesquisas analíticas, empíricas ou experimentais baseadas em economia, psicologia e outras disciplinas. É bilíngüe (inglês e francês)
Internacional 
TABELA 2 (continuação)

NOME DA REVSTA

ÁREA RESUMIDA DE ENFOQUE EXPRESSA NO EDITORIAL E/OU COMPREENDIDA

50. Cost Engineering
Artigos gerais, basicamente empíricos, sobre custos, suas metodologias e técnicas relacionadas. Apesar de ser uma revista voltada mais para a engenharia, é uma importante publicação também para os contadores que trabalham com custos e análise gerencial

\begin{tabular}{ll}
\hline 51. CPA Journal (The) & Aspectos relacionados com a auditoria e a contabilidade dirigidos ao CPA \\
\hline 52. CPA Letter & Aspectos relacionados com a profissão de contador público certificado nos \\
& EUA. O AlCPA publica também uma newsletter mensal - The Practing CPA, o \\
& informativo Tax Adviser, também mensal, que é especifico para aconselhamento \\
& fiscal e de tributos e um outro informativo bimestral, Infotech Update, que \\
& focaliza tecnologia da informação relacionada com a prática
\end{tabular}

53. Critical Perspectives in Accounting

Procura enfatizar que as teorias e as práticas convencionais estão desajustadas para os desafios do moderno ambiente onde a contabilidade e os comportamentos corporativos estão conectados com muitos problemas sociais, por exemplo, problemas de alocação, de distribuição, e ecológicos

54. EDPACS EDP - Audit, Control, and Security Newsletter

Focaliza a auditoria, o controle e a segurança de sistemas. Aspectos gerais Local sobre tecnologia relacionada com a auditoria e sistemas.

Internacional 5. Education: An International Journal

Dedicado à publicação de artigos baseados em pesquisa e em outras Internacional informações chaves para o desenvolvimento da educação em contabilidade. Faz também resenha de livros.

56. European Accounting Review (The)

Não está especificado no editorial, mas a revista publica normalmente Internacional todos os assuntos relacionados com a contabilidade e auditoria. Também faz resenha de livros.

57. Financial Accountability and Management

Publica artigos com uma abordagem interdisciplinar - economia, ciência Internacional política, administração pública e social, contabilidade, auditoria, etc.-

58. Government Accountants Journal (The)

Focaliza todos os niveis da administração financeira governamental nos Estados Unidos

Local Vários aspectos da contabilidade. Aspectos da profissão contábil internacional, Internacional

59. IFAC Quarterly educação, ética, aspectos do setor público e auditoria. Publica também uma newsletter especifica sobre educação e outras publicações on-line.

60. Information Systems Control Journal

Aplicações em sistemas de informação e auditoria, tecnologia da informação

Local e controle

\begin{tabular}{llll}
\hline 61. Internal Auditing & Aspectos gerais da auditoria interna e da contabilidade & Local \\
\hline 62. Internal Auditor & Aspectos gerais da auditoria interna e da contabilidade & Local \\
\hline $\begin{array}{l}\text { 63. International Journal of } \\
\begin{array}{l}\text { Accounting and Business } \\
\text { Society }\end{array}\end{array}$ & $\begin{array}{l}\text { Aspectos organizacionais, comportamentais e sociais relacionados com a } \\
\text { contabilidade. }\end{array}$ & Internacional \\
\hline
\end{tabular}

64. International Journal of Accounting (The)

Objetiva a compreensão da teoria e da prática contábil numa perspectiva e pontos de vistas intemacionais. Reconhece que a contabilidade internacional é influenciada Internacional por uma variedade de forças - governamental, política e econômica. Colabora com o entendimento do presente da potencial aptidão da contabilidade em registrar e interpretar as transações econômicas internacionais. Procura uma ampla visão das origens e do desenvolvimento da contabilidade e enfatiza a crescente interdeendência global. Também faz resenha de livros sobre contabilidade. 
65. International Journal of Government Auditing

Expõe os avanços das técnicas e procedimentos da auditoria governamental. Enfatiza os aspectos pragmáticos da auditoria do setor público, incluindo casos de estudos, idéias e novas metodologias ou detalhes dos programas de treinamento em auditoria. Artigos teóricos não são normalmente aceitos

66. International Journal of Intelligent Systems in Accounting, Finance \& Management

Focaliza o desenvolvimento dos sistemas inteligentes e da tecnologia da informação aplicados à contabilidade, às finanças e à auditoria. Sistemas de suporte a decisão, sistemas especialistas, redes neurais, sistemas nebulosos, algoritmos genéticos e inteligência artificial.

\begin{tabular}{llll}
\hline 67. Irish Accounting Review & Aspectos gerais da contabilidade e da educação da República da Irlanda & Local \\
\hline $\begin{array}{l}\text { 68. Issues in Accounting } \\
\text { Education }\end{array}$ & $\begin{array}{l}\text { Publica pesquisas, comentários, resenhas de livros e recursos didáticos } \\
\text { que ajudam os professores no conhecimento e na compreensão de } \\
\text { importantes assuntos/tópicos relacionados com o desenvolvimento do } \\
\text { ensino na contabilidade. }\end{array}$
\end{tabular}

69. Journal of International Taxation

70. Journal of Accountancy

71. Journal of Accounting \& Economics
Focaliza sofisticadas análises e atualidades do planejamento dos impostos nos EUA e em outros vinte países do mundo.
Internacional

As últimas notícias e desenvolvimentos relacionados com o campo da contabilidade.

Emprega análise econômica nos problemas contábeis. Focaliza a análise na determinação dos padrões contábeis, a regulação governamental e a "disclosure" corporativa, o conteúdo da informação e o papel dos números contábeis no mercado financeiro, o papel da contabilidade nos contratos financeiros e o monitoramento das relações da teoria do agente, a regulação governamental da profissão contábil, amostragem estatística, a teoria da firma e o papel da contabilidade dentro da organização.
72. Journal of Accounting and Public Policy
Procura focalizar análises empíricas ou teóricas e os efeitos da contabilidade nas politicas públicas e vice-versa. Enfatiza a contabilidade como uma interface dentro da economia, administração pública, ciência política, psicologia social, sociologia e direito.
73. Journal of Accounting Case Research
Estudos de casos com anotações especiais sobre cada caso. Focaliza a contabilidade geral e auditoria e outros tópicos relacionados com a educação contábil e negócios

74. Journal of Accounting Education

(1)

\section{Journal of Accounting} Information System

Novo jornal que focaliza a relação entre a contabilidade e a tecnologia de informação, novas técnicas e a integração da contabilidade com TI.

Internacional

76. Journal of Accounting Literature

Duplo objetivo 1) prover uma síntese de pesquisas contábeis com objetivo de ajudar acadêmicos na compreensão, conhecimento e avaliação de pesquisas contábeis que não são da sua área de conhecimento e; 2) publicar artigos apresentados na Universidade da Flórida em assuntos relacionados com a contabilidade e auditoria.

77. Journal of Accounting Research

78. Journal of Accounting, Auditing, \& Finance
Publica artigos de todos os assuntos relacionados com contabilidade e auditoria. Uma vez por ano publica um suplemento com um tema específico

Publica artigos sobre contabilidade, finanças e auditoria que focalizem trabalhos empíricos, teóricos e experimentais - normativos e positivos - que possam aprimorar o conhecimento da contabilidade e finanças. Internacional

Internacional

(1)

Internacional

Internacional Internacional 
TABELA 2 (continuação)

NOME DA REVSTA

ÁREA RESUMIDA DE ENFOQUE EXPRESSA NO EDITORIAL EIOU COMPREENDIDA

79. Journal of American Taxation Association (The)

Publica artigos que focalizam os aspectos legais, a pesquisa teórica e quantitativa e descritiva que se relacionam com impostos e a tributação. Pesquisas educacionais que divulgam a informação e o conhecimento do ensino em tributação.

80. Journal of Applied Accounting Research

81. Journal of Bank Cost \& Management

82. Journal of Business Finance \& Accounting

Aspectos gerais da contabilidade e auditoria

Internacional

Local

Focaliza aspectos da indústria de serviços financeiros, desregulamentação bancária, custos e aspectos gerencias e a análise financeira

Publica os avanços acadêmicos e da prática profissional da administração financeira, do controle e "accountability" baseado em análises teóricas e empíricas. Focaliza a teoria das finanças, contabilidade financeira, contabilidade gerencial e controle, auditoria e desempenho.

83. Journal of Corporate Accounting \& Finance (The)

84. Journal of Cost Analysis

Publica artigos relacionados com a contabilidade corporativa para executivos financeiros, auditores externos e contadores de corporações.

Local finceiros, auditores externos e contadores de corporaços.

Publica artigos sobre a análise e a estimativa de custos para acadêmicos e Local profissionais

85. Journal of Cost Management

Focaliza principalmente aspectos relacionados com ABC/ABM, Target Costing, Just-in-time, Teoria da Restrições e outros aspectos relacionados com a necessidade de informações internas para a tomada de decisão.

86. Journal of Financial Statement Analysis

Busca entender e interpretar as atividades da empresa num contexto dos demonstrativos financeiros. Faz análises interdisciplinares com ênfase na contabilidade, finanças e estratégia de negócios, legislação, estatística, impostos, auditoria e economia.

87. Journal of Forensic Accounting, Audit, Fraud and Taxation

Artigos sobre contabilidade forense. Principalmente fraude em contabilidade $e$ auditoria, manipulação de ganhos e evasão de impostos, falência, violação da US-GAAP, fraude em demonstrações financeiras e economia subterrânea.

88. Journal of Information Systems

Busca aprimorar a pesquisa, educação e prática dos sistemas de informações contábeis. Pesquisa acadêmica, estudos educacionais e prática de sistemas de informações contábeis.

Local

Local

Local

Local

89. Journal of International Accounting, Auditing e impostos e serviços de consultoria. Taxation

90. Journal of International Financial Management and Accounting

91. Journal of Management Accounting Research

92. Journal of Public Budgeting Accounting \& Financial Management

93. Journal of Taxation

Aspectos internacionais da administração financeira e da contabilidade, bem como serviços financeiros e bancários, auditoria e impostos.

Internacional

\author{
comos.
}

Publica artigos analíticos e empíricos relacionados com os relatórios internos,

Internacional tomada de decisão e a interface entre relatórios internos e externos de quaisquer tipos de organizações

Teorias e práticas nos campos do orçamento público, contabilidade

Local governamental e administração financeira. 
94. Journal of Taxation of Exempt Organizations
Focaliza informações práticas e idéias no campo legal, de impostos, contabilidade e finanças. Aspectos sobre reestruturação empresarial e necessidades no ambiente regulatório.
Local

Local

Artigos gerais sobre contabilidade gerencial, contabilidade de custos e sistemas de informação. Aspectos gerais sobre contabilidade exclusiva para CPAs

95. Management Accountant Aspectos gerais da contabilidade gerencial e custos Local

\begin{tabular}{lll} 
96. Management Accountant & Aspectos gerais da contabilidade gerencial e custos & Local \\
\hline $\begin{array}{l}\text { 97. Management Accounting - } \\
\text { London }\end{array}$ & $\begin{array}{l}\text { Artigos gerais sobre contabilidade, principalmente contabilidade gerencial, } \\
\text { custos e sistemas para decisão. }\end{array}$ & Internacional \\
\hline $\begin{array}{l}\text { 98. Management Accounting } \\
\text { Quarterly }\end{array}$ & $\begin{array}{l}\text { Objetiva fazer uma ponte entre o mundo dos negócios e o mundo acadêmico, } \\
\text { apresentando pesquisas aplicadas e acadêmicas, principalmente sobre ABC/ } \\
\text { ABM e Target Costing. Revista recente do IMA. }\end{array}$
\end{tabular}

99. Management Accounting Artigos sobre contabilidade gerencial, incluindo estudos de caso, estudo de Internacional Research campo, estudos empíricos e comentários e notas.

100. Managerial Auditing Journal

Objetiva identificar as melhores técnicas de auditoria usadas pelas Internacional organizações ao redor do mundo. Enfatiza estudos de casos, auditoria ambiental, considerações éticas e o processo social da auditoria.

101. National Public Aspectos gerais sobre contabilidade e auditoria da área pública. Publica uma Local Accountant newsletter

Aspectos gerais sobre impostos nos EUA

Local

102. National Tax Journal

Para estudantes de contabilidade com objetivo de aprimorar a compreensão da dinâmica e da necessidade das empresas empregadoras, focalizando

Local

103. New Accountant como contadores/auditores deveriam se preparar para se tornarem excelentes profissionais.

104. Pacific Accounting Publica uma grande variedade de tópicos relacionados com a contabilidade Internacional Review e finanças. Faz resenha de livros

Assuntos relacionados com a contabilidade, finanças, tributação e economia

Local

105. Petroleum Accounting and Financial em empresas de petróleo e gás.

Management Journal

106. Practical Accountant

Impostos, aconselhamento monetário, Contabilidade, relatório de auditoria

Local e planejamento financeiro

107. Practical Tax Strategies

Focaliza aspectos da redução de impostos e da regulação num enfoque Local estratégico

108. Research in Accounting

Relaciona ética e contabilidade. Discute a ética aplicada na auditoria, na Internacional Ethics Contabilidade, pelos profissionais, e na educação.

109. Research in Accounting in Emerging Economies

Dedica atenção ao estudo de problemas e assuntos relacionados com a Internacional contabilidade de países emergentes, principalmente aqueles que poderão melhorar a alocação eficiente de recursos escassos através do mercado de capital. Focaliza aspectos particulares da contabilidade e da auditoria desses países que a literatura internacional ignora.

110. Research in Accounting Regulation

Discute a política de regulação amplamente definida como: alta regulação, regulação governamental, regulação econômica, evidenciação, estrutura Internacional educacional, modelagens, casos de litígios e leis que se relacionam com a contabilidade 
TABELA 2 (continuação)

NOME DA REVISTA

ÁREA RESUMIDA DE ENFOQUE EXPRESSA NO EDITORIAL EIOU COMPREENDIDA

111. Review of Accounting Information Systems

Procura discutir como o computador, a Internet e o comércio eletrônico estão influenciando a prática contábil e a educação. Cobre aspectos relativos a sistemas contábeis e faz análises de softwares usados na contabilidade

112. Review of Accounting Studies

113. Review of Quantitative Finance and Accounting

Pesquisa acadêmica em contabilidade, incluindo aspectos experimentais, teóricos e empíricos.

Pesquisas que apresentem resultados baseados em aplicações empíricas. Pesquisas puramente metodológicas e teóricas com importante potencial de aplicabilidade também são publicadas.

\begin{tabular}{lll}
\hline $\begin{array}{l}\text { 114. Singapore Accountant } \\
\text { 115. Strategic Finance (Ex } \\
\text { Management Accounting } \\
\text { - USA) }\end{array}$ & $\begin{array}{l}\text { Focaliza aspectos da contabilidade, finanças e negócios numa perspectiva } \\
\text { profissional. }\end{array}$ & Internacional \\
\hline $\begin{array}{l}\text { 116. Studies in Managerial } \\
\text { and Financial Accounting }\end{array}$ & $\begin{array}{l}\text { Aspectos gerais sobre contabilidade. Cada volume focaliza um tema } \\
\text { específico sendo difícil de estabelecer um parâmetro exato de sua } \\
\text { abrangência. Melhor visitar o sistema (JAIPRESS.com) e verificar a relação } \\
\text { de artigos e tema de cada volume. }\end{array}$ & Internacional \\
\hline $\begin{array}{l}\text { 117. Studies in the } \\
\text { Acvelopment of }\end{array}$ & $\begin{array}{l}\text { Nova Revista da Jai Press. Planeja publicar monografias originais e pesquisas } \\
\text { em assuntos relacionados com o desenvolvimento da contabilidade como } \\
\text { disciplina, sua natureza, significado e fundamentos das proposições e idéias } \\
\text { contábeis }\end{array}$ \\
\hline $\begin{array}{l}\text { 118. Valuation } \\
\text { Internacional }\end{array}$ \\
\hline
\end{tabular}

ENFOQUE

Local

Internacional

Local

(n)




\section{TABELA 3}

\section{DIMENSÄO DOS MÉTODOS QUANTITATIVOS APLICADOS, DOSTIPOS DE ENFOQUES CONTÁBEIS, DAS ÁREAS PREDOMINANTES E FREQŪÊNCIA DA PUBLICAÇĀO}

\section{MOME DA REVISTA}

MÉTTODOS

TIPOS DE

AREA DE ENFOQUE FREOUENCIA DA QUANTITATIVOS

1. Abacus: A Joumal of

Médio

Teórico/Empirico

Contabilidade e

Duas vezes Accounting. Finance, and Business Studies

Mercado Financeiro

2. Academy of Accoumting

Razoável

Teorico/Emplrico

Contabilidade Geral

Duas vezes and Financial Studies Joumal

\begin{tabular}{|c|c|c|c|c|}
\hline 3. Accountancy & Pouco/nenhum & Protissional & Auditoria Contabilidade & Doze vezes \\
\hline 4. Accountancy Ireland & Pouco/nenhum & Profissional & - Contabilidade Geral & Sols vezos \\
\hline 5. Accountant (The) & Pouco/henhum & Profissional & Contabilidade Geral & Doze vezes \\
\hline 6. Accounting \& Business & Pouco/nenhum & Profissional & Contabilidade Geral & Oito vezes \\
\hline $\begin{array}{l}\text { 7. Accounting and Businoss } \\
\text { Research }\end{array}$ & Razodivol & Tebtico & Contabisdade Geral & Seis vezes \\
\hline $\begin{array}{l}\text { 8. Accounting and Business } \\
\text { Review }\end{array}$ & Razodvel & Teorico & Contabilidade Geral & Dusas vezes \\
\hline 9. Accounting and Finance & Razodvel & Tebrico & Contabilidade Geral & Trôs vezes \\
\hline $\begin{array}{l}\text { 10. Accounting and Public } \\
\text { Interest }\end{array}$ & Pouco/nenhum & Teórico & Ética & Duas vezes \\
\hline $\begin{array}{l}\text { 11. Accounting Business and } \\
\text { Financial History }\end{array}$ & Pouco/nerhum & Tedrico & "Historia & Tres vezes \\
\hline $\begin{array}{l}\text { 12. Accounting Education: A } \\
\text { Journal of Theory, Practice } \\
\text { \& Research }\end{array}$ & Poucoo/nenhum & Teórico & $\begin{array}{c}\text { Educaçăo } \\
\text {. }\end{array}$ & Duas vezes \\
\hline $\begin{array}{l}\text { 13. Accounting Education: A } \\
\text { International Joumal }\end{array}$ & Pouco/nenhum & Teorico & Educaglo & Quatro vozes \\
\hline $\begin{array}{l}\text { 14. Accounting Educators } \\
\text { Journal (tho) }\end{array}$ & Pouco/nenhum & Teórico & Educaçăo & Duas vezes \\
\hline 15. Accounting Enquires & Razodvet & Teorico & Contabirdade Geral & Duas vezes \\
\hline 16. Accounting Forum & Pouco/henhum & Tebrico & Contabildade Geral & Quatro vezes \\
\hline $\begin{array}{l}\text { 17. Accounting Historians } \\
\text { VJoumal (Tho) }\end{array}$ & Pouco/nenhum & Teठrico & Historila & Duas vezes \\
\hline 18. Accounting Horizons & Razodivel & Tebrico/Empírico & Contabilidade Geral & Quatro vezes \\
\hline $\begin{array}{l}\text { 19. Accounting Research } \\
\text { Journal }\end{array}$ & Razodivel & Teórico/Empirico & Contabilidade Geral & Duas vezes \\
\hline 20. Accounting Review (The) & Solisticado & Toórlco/Empirico & $\begin{array}{l}\text { Contabilidado e } \\
\text { Mercado Financeiro }\end{array}$ & Qujatro vezes \\
\hline $\begin{array}{l}\text { 21. Accounting Technology } \\
\text { Magazine (Ex Computers } \\
\text { in Accounting) }\end{array}$ & Pouco/nenhum & Profissional & Tecnologia e Sistemas & Onze vezes \\
\hline
\end{tabular}


TABELA 3 (continuação)

\begin{tabular}{|c|c|c|c|c|}
\hline NOME DA REVISTA & $\begin{array}{l}\text { MÉTODOS } \\
\text { QUANTITATIVOS }\end{array}$ & $\begin{array}{l}\text { TIPOS DE } \\
\text { ENFOQUES }\end{array}$ & $\begin{array}{l}\text { AREA DE ENFOQUE } \\
\text { PREDOMINANTE }\end{array}$ & $\begin{array}{l}\text { FREQÜÊNCIA DA } \\
\text { PUBLICAÇÄOO }\end{array}$ \\
\hline Accounting Today & Pouco/nenhum & Profissional & Contabilidade Geral & Vinte e quatro vezes \\
\hline $\begin{array}{l}\text { Accounting, Auditing \& } \\
\text { Accountability Journal }\end{array}$ & Médio & Teórico/Empírico & Auditoria e Sociedade & Cinco vezes \\
\hline $\begin{array}{l}\text { Accounting, Management } \\
\text { and Information Technologies }\end{array}$ & Pouco/nenhum & Teórico/Empírico & Tecnologia e Sistemas & Quatro vezes \\
\hline $\begin{array}{l}\text { Accounting, Organizations } \\
\text { and Society }\end{array}$ & Razoável & Teórico/Empírico & Contabilidade Geral & Sete/oito vezes \\
\hline 6. Advances in Accounting & Razoável & Teórico/Empírico & Contabilidade Geral & Uma vez \\
\hline $\begin{array}{l}\text { Advances in Accounting } \\
\text { Behavioral Research }\end{array}$ & Razoável & Teórico/Empírico & $\begin{array}{l}\text { Contabilidade } \\
\text { Comportamental }\end{array}$ & Uma vez \\
\hline $\begin{array}{l}\text { Advances in Accounting } \\
\text { Educational Teaching and } \\
\text { Curriculum Innovations }\end{array}$ & Pouco/nenhum & Teórico/Empírico & Educação & Uma vez \\
\hline $\begin{array}{l}\text { 9. Advances in Accounting } \\
\text { Information Systems }\end{array}$ & Razoável & Teórico/Empírico & $\begin{array}{l}\text { Sistemas de } \\
\text { informações }\end{array}$ & Uma vez \\
\hline $\begin{array}{l}\text { Advances in } \\
\text { Environmental and } \\
\text { Accounting Management }\end{array}$ & Pouco/nenhum & Teórico/Empírico & Meio Ambiente & Uma vez \\
\hline $\begin{array}{l}\text { 1. Advances in International } \\
\text { Accounting }\end{array}$ & Pouco/nenhum & Teórico/Empírico & $\begin{array}{l}\text { Contabilidade } \\
\text { Internacional }\end{array}$ & Uma vez \\
\hline $\begin{array}{l}\text { 2. Advances in Management } \\
\text { Accounting }\end{array}$ & Sofisticado & Teórico/Empírico & $\begin{array}{c}\text { Contabilidade } \\
\text { Gerencial e Custos }\end{array}$ & Uma vez \\
\hline $\begin{array}{l}\text { 3. Advances in Public } \\
\text { Interest Accounting }\end{array}$ & Pouco/nenhum & Teórico & $\begin{array}{l}\text { Contabilidade e } \\
\text { Sociedade }\end{array}$ & Um vez \\
\hline $\begin{array}{l}\text { Advances in Quantitative } \\
\text { Analysis of Finance and } \\
\text { Accounting }\end{array}$ & Sofisticado & Teórico/Empírico & Contabilidade Geral & Uma vez \\
\hline 5. Advances in Taxation & Razoável & Teórico/Empírico & Impostos & Uma vez \\
\hline 6. Asia Review of Accounting & Razoável & Teórico & Contabilidade Geral & Duas vezes \\
\hline 7. Auditing, Litigation and Tax & Pouco/nenhum & Teórico & Impostos & Seis vezes \\
\hline $\begin{array}{l}\text { 8. Auditing: A Journal of } \\
\text { Practice \& Theory }\end{array}$ & Razoável & Teórico/Empírico & Auditoria & Três vezes \\
\hline $\begin{array}{l}\text { 9. Australian Accounting } \\
\text { Review }\end{array}$ & Pouco/nenhum & Teórico & Contabilidade Geral & Três vezes \\
\hline 0. Australian CPA & Pouco/nenhum & Profissional & Contabilidade Geral & Doze vezes \\
\hline $\begin{array}{l}\text { 1. Behavioral Research in } \\
\text { Accounting }\end{array}$ & Pouco/nenhum & Teórico & Contabilidade Geral & Uma vez \\
\hline British Accounting Rev & Razoável & Teórico/Empírico & Contabilidade Geral & Quatro vezes \\
\hline
\end{tabular}




\section{NOME DA REVISTA}

43. BusinesFinance (Ex Controller Magazine)

\begin{tabular}{l} 
44. CA Magazine \\
45. CGA Magazine \\
46. Chartered Accountant (The) \\
47. China Accounting and \\
Finance Review \\
48. CMA Canadá \\
Management \\
\hline 49. Contemporary Accounting \\
Research
\end{tabular}

50. Cost Engineering
MÉTODOS QUANTITATIVOS

\begin{tabular}{|c|c|c|c|c|}
\hline 51. CPA Journal (The) & Pouco/nenhum & Profissional & Auditoria & Doze vezes \\
\hline 52. CPA Letter & Pouco/nenhum & Profissional & Contabilidade Geral & Vinte e duas vezes \\
\hline $\begin{array}{l}\text { 53. Critical Perspectives in } \\
\text { Accounting }\end{array}$ & Pouco/nenhum & Teórico & Contabilidade Geral & Seis vezes \\
\hline 54. EDPACS & Pouco/nenhum & Profissional & Tecnologia e Sistemas & Vinte quatro vezes \\
\hline $\begin{array}{l}\text { 55. Education: An International } \\
\text { Journal }\end{array}$ & Pouco/nenhum & Teórico/Empírico & Educação & Quatro vezes \\
\hline $\begin{array}{l}\text { 56. European Accounting } \\
\text { Review (The) }\end{array}$ & Pouco/nenhum & Teórico & Contabilidade Geral & Quatro vezes \\
\hline $\begin{array}{l}\text { 57. Financial Accountability } \\
\text { and Management }\end{array}$ & Pouco/nenhum & Teórico & Auditoria & Quatro vezes \\
\hline $\begin{array}{l}\text { 58. Government Accountants } \\
\text { Journal (The) }\end{array}$ & Pouco/nenhum & Profissional & Fiscal//mpostos & Quatro vezes \\
\hline 59. IFAC Quarterly & Pouco/nenhum & Teórico & $\begin{array}{l}\text { Normas de } \\
\text { Contabilidade }\end{array}$ & Quatro vezes \\
\hline $\begin{array}{l}\text { 60. Information Systems } \\
\text { Control Journal }\end{array}$ & Pouco/nenhum & Profissional & Tecnologia e Sistemas & Seis vezes \\
\hline 61. Internal Auditing & Pouco/nenhum & Profissional & Auditoria & Seis vezes \\
\hline 62. Internal Auditor & Pouco/nenhum & Profissional & Auditoria & Seis vezes \\
\hline $\begin{array}{l}\text { 63. International Journal of } \\
\text { Accounting (The) }\end{array}$ & Pouco/nenhum & Empírico & $\begin{array}{c}\text { Contabilidade } \\
\text { Financeira/Mercados }\end{array}$ & Quatro vezes \\
\hline $\begin{array}{l}\text { 64. International Journal of } \\
\text { Government Auditing }\end{array}$ & Pouco/nenhum & Profissional & Auditoria & Quatro vezes \\
\hline
\end{tabular}


TABELA 3 (continuação)

NOME DA REVISTA

65. International Journal of Intelligent Systems in

Accounting, Finance \&

Management

\begin{tabular}{|c|c|c|c|c|}
\hline 66. Irish Accounting Review & Razoável & Profissional & Contabilidade Geral & Quatro vezes \\
\hline $\begin{array}{l}\text { 67. Issues in Accounting } \\
\text { Education }\end{array}$ & Pouco/nenhum & Teórico/Empírico & Educação & Quatro vezes \\
\hline $\begin{array}{l}\text { 68. Journal of International } \\
\text { Taxation }\end{array}$ & Pouco/nenhum & Profissional & Impostos & Doze vezes \\
\hline 69. Journal of Accountancy & Pouco/nenhum & Profissional & Contabilidade Geral & Doze vezes \\
\hline $\begin{array}{l}\text { 70. Journal of Accounting \& } \\
\text { Economics }\end{array}$ & Sofisticado & Teórico/Empírico & $\begin{array}{c}\text { Contabilidade } \\
\text { Financeira Mercados }\end{array}$ & Seis vezes ao ano \\
\hline $\begin{array}{l}\text { 71. Journal of Accounting and } \\
\text { Business Society }\end{array}$ & Pouco/nenhum & Teórico & Contabilidade Geral & Duas vezes \\
\hline $\begin{array}{l}\text { 72. Journal of Accounting and } \\
\text { Public Policy }\end{array}$ & Razoável & Teórico/Empírico & Contabilidade Geral & $\begin{array}{c}\text { Quatro vezes } \\
\text { por ano }\end{array}$ \\
\hline $\begin{array}{l}\text { 73. Journal of Accounting } \\
\text { Case Research }\end{array}$ & Pouco/nenhum & Profissional & Educação & Duas vezes \\
\hline $\begin{array}{l}\text { 74. Journal of Accounting } \\
\text { Education }\end{array}$ & Pouco/nenhum & Teórico/Empírico & Educação & Quatro vezes \\
\hline $\begin{array}{l}\text { 75. Journal of Accounting } \\
\text { Information System }\end{array}$ & Pouco/nenhum & Profissional & $\begin{array}{l}\text { Tecnologia e } \\
\text { Sistemas }\end{array}$ & Três vezes \\
\hline $\begin{array}{l}\text { 76. Journal of Accounting } \\
\text { Literature }\end{array}$ & Pouco/nenhum & Teórico & Contabilidade Geral & Uma vez \\
\hline $\begin{array}{l}\text { 77. Journal of Accounting } \\
\text { Research }\end{array}$ & Razoável & Teórico/Empírico & Contabilidade Geral & Três vezes \\
\hline $\begin{array}{l}\text { 78. Journal of Accounting, } \\
\text { Auditing, \& Finance }\end{array}$ & Pouco/nenhum & Teórico/Empírico & Contabilidade Geral & Quatro vezes \\
\hline $\begin{array}{l}\text { 79. Journal of American } \\
\text { Taxation Association (The) }\end{array}$ & Razoável & Teórico & Impostos & Três vezes \\
\hline $\begin{array}{l}\text { 80. Journal of Applied } \\
\text { Accounting Research }\end{array}$ & Sofisticado & Teórico/Empírico & $\begin{array}{c}\text { Contabilidade } \\
\text { Financeira/Mercados }\end{array}$ & Três vezes \\
\hline $\begin{array}{l}\text { 81. Journal of Bank Cost \& } \\
\text { Management }\end{array}$ & Razoável & Teórico & $\begin{array}{l}\text { Contabilidade do } \\
\text { Sistema Financeiro }\end{array}$ & Três vezes \\
\hline $\begin{array}{l}\text { 82. Journal of Business } \\
\text { Finance \& Accounting }\end{array}$ & Razoável & Teórico/Empírico & Contabilidade Geral & Cinco vezes \\
\hline $\begin{array}{l}\text { 83. Journal of Corporate } \\
\text { Accounting \& Finance (The) }\end{array}$ & Pouco/nenhum & Teórico & $\begin{array}{c}\text { Contabilidade } \\
\text { Financeira/Mercados }\end{array}$ & Seis vezes \\
\hline 84. Journal of Cost Analysis & Razoável & Empírico & Gerencial/Custos & Duas vezes \\
\hline
\end{tabular}

TIPOS DE ÁREA DE ENFOQUE FREQÜÊNCIA DA ENFOQUES PREDOMINANTE QUANTITATIVOS

Empírico

Tecnologia e Sistemas

Quatro vezes PUBLICAÇÄO 
ÁREA DE ENFOQUE FREQÜÊNCIA DA QUANTITATIVOS ENFOQUES PREDOMINANTE PUBLICAÇÄO

\begin{tabular}{|c|c|c|c|c|}
\hline $\begin{array}{l}\text { 85. Journal of Cost } \\
\text { Management }\end{array}$ & Pouco/nenhum & Profissional & Gerencial/Custos & Seis vezes \\
\hline $\begin{array}{l}\text { 86. Journal of Financial } \\
\text { Statement Analysis }\end{array}$ & Sofisticado & Profissional & $\begin{array}{c}\text { Contabilidade } \\
\text { Financeira/Mercados }\end{array}$ & Quatro vezes \\
\hline $\begin{array}{l}\text { 87. Journal of Forensic } \\
\text { Accounting, Audit, Fraud } \\
\text { and Taxation }\end{array}$ & Pouco/nenhum & Teórico/empírico & Contabilidade Geral & Duas vezes \\
\hline $\begin{array}{l}\text { 88. Journal of Information } \\
\text { Systems }\end{array}$ & Razoável & Profissional & Tecnologia e Sistemas & Duas vezes \\
\hline $\begin{array}{l}\text { 89. Journal of International } \\
\text { Accounting, Auditing e } \\
\text { Taxation }\end{array}$ & Pouco/nenhum & Teórico & Auditoria & $\begin{array}{l}\text { Duas vezes por } \\
\text { ano }\end{array}$ \\
\hline $\begin{array}{l}\text { 90. Journal of International } \\
\text { Financial Management and } \\
\text { Accounting }\end{array}$ & Pouco/nenhum & Teórico & Contabilidade Geral & Três vezes por ano \\
\hline $\begin{array}{l}\text { 91. Journal of Management } \\
\text { Accounting Research }\end{array}$ & Razoável & Teórico & $\begin{array}{c}\text { Contabilidade } \\
\text { Gerencial e Custos }\end{array}$ & Uma vez por ano \\
\hline $\begin{array}{l}\text { 92. Journal of Public } \\
\text { Budgeting Accounting \& } \\
\text { Financial Management }\end{array}$ & Razoável & Teórico & Contabilidade Pública & Duas vezes \\
\hline 93. Journal of Taxation & Pouco/nenhum & Profissional & Impostos & Doze vezes \\
\hline $\begin{array}{l}\text { 94. Journal of Taxation of } \\
\text { Exempt Organizations }\end{array}$ & Pouco/nenhum & Profissional & Impostos & Seis vezes \\
\hline 95. Management Accountant & Pouco/nenhum & Profissional & $\begin{array}{l}\text { Contabilidade } \\
\text { Gerencial e Custos }\end{array}$ & Quatro vezes \\
\hline 96. Management Accountant & Pouco/nenhum & Profissional & $\begin{array}{l}\text { Contabilidade } \\
\text { Gerencial e Custos }\end{array}$ & Doze vezes \\
\hline 97. Management Accounting & Pouco/nenhum & Profissional & $\begin{array}{l}\text { Contabilidade } \\
\text { Gerencial e Custos }\end{array}$ & Doze vezes \\
\hline $\begin{array}{l}\text { 98. Management Accounting } \\
\text { Quarterly }\end{array}$ & Pouco/nenhum & Teórico/Empírico & $\begin{array}{l}\text { Contabilidade } \\
\text { Gerencial e Custos }\end{array}$ & Quatro vezes \\
\hline $\begin{array}{l}\text { 99. Management Accounting } \\
\text { Research }\end{array}$ & Razoável & Teórico/Empírico & $\begin{array}{l}\text { Contabilidade } \\
\text { Gerencial e Custos }\end{array}$ & Quatro vezes \\
\hline $\begin{array}{l}\text { 100. Managerial Auditing } \\
\text { Journal }\end{array}$ & Pouco/nenhum & Teórico & Auditoria & Duas vezes \\
\hline $\begin{array}{l}\text { 101. National Public } \\
\text { Accountant }\end{array}$ & Pouco/nenhum & Profissional & Contabilidade Pública & Dez vezes \\
\hline 102. National Tax Journal & Razoável & Profissional & Impostos & Quatro \\
\hline
\end{tabular}


TABELA 3 (continuação)

\begin{tabular}{|c|c|c|c|c|}
\hline NOME DA REVISTA & $\begin{array}{c}\text { MÉTODOS } \\
\text { QUANTITATIVOS }\end{array}$ & $\begin{array}{l}\text { TIPOS DE } \\
\text { ENFOQUES }\end{array}$ & $\begin{array}{l}\text { ÁREA DE ENFOQUE } \\
\text { PREDOMINANTE }\end{array}$ & $\begin{array}{c}\text { FREQÜÊNCIA DA } \\
\text { PUBLICAÇÄO }\end{array}$ \\
\hline 04. Pacific Accounting Review & Pouco/nenhum & Teórico/Empírico & Contabilidade Geral & Duas vezes por a \\
\hline $\begin{array}{l}\text { 05. Petroleum Accounting } \\
\text { and Financial Management } \\
\text { Journal }\end{array}$ & Pouco/nenhum & Teórico & $\begin{array}{l}\text { Contabilidade } \\
\text { Especifica }\end{array}$ & Três vezes por a \\
\hline
\end{tabular}

\begin{tabular}{|c|c|c|c|c|}
\hline 106. Practical Accountant & Pouco/nenhum & Profissional & Contabilidade Geral & Doze vezes \\
\hline 107. Practical Tax Strategies & Pouco/nenhum & Profissional & Impostos & Doze vezes \\
\hline $\begin{array}{l}\text { 108. Research in Accounting } \\
\text { Ethics }\end{array}$ & Pouco/nenhum & Teórico & Ética & Uma vez \\
\hline $\begin{array}{l}\text { 109. Research in Accounting } \\
\text { in Emerging Economies }\end{array}$ & Pouco/nenhum & Teórico/Empírico & $\begin{array}{l}\text { Contabilidade } \\
\text { Internacional }\end{array}$ & Uma vez \\
\hline $\begin{array}{l}\text { 110. Research in Accounting } \\
\text { Regulation }\end{array}$ & Pouco/nenhum & Teórico & $\begin{array}{c}\text { Contabilidade } \\
\text { Financeira/Mercados }\end{array}$ & Uma vez \\
\hline $\begin{array}{l}\text { 111. Review of Accounting } \\
\text { Information Systems }\end{array}$ & Pouco/nenhum & Profissional & Tecnologia e Sistemas & Duas vezes \\
\hline $\begin{array}{l}\text { 112. Review of Accounting } \\
\text { Studies }\end{array}$ & Sofisticado & Teórico/Empírico & $\begin{array}{c}\text { Contabilidade } \\
\text { Financeira/Mercados }\end{array}$ & Quatro vezes \\
\hline $\begin{array}{l}\text { 113. Review of Quantitative } \\
\text { Finance and Accounting }\end{array}$ & Sofisticado & Teórico/Empírico & $\begin{array}{c}\text { Contabilidade } \\
\text { Financeira/Mercados }\end{array}$ & Duas vezes \\
\hline $\begin{array}{l}\text { 114. Singapore } \\
\text { AccountantWoman CPA }\end{array}$ & Pouco/nenhum & Profissional & Contabilidade Geral & Seis vezes \\
\hline $\begin{array}{l}\text { 115. Strategic Finance (Ex } \\
\text { Management Accounting } \\
\text { - USA) }\end{array}$ & Pouco/nenhum & Profissional & Contabilidade Geral & Doze vezes \\
\hline $\begin{array}{l}\text { 116. Studies in Managerial } \\
\text { and Financial Accounting }\end{array}$ & Razoável & Teórico/Empírico & Contabilidade Geral & Uma vez \\
\hline $\begin{array}{l}\text { 117. Studies in the } \\
\text { Development of } \\
\text { Accounting thought }\end{array}$ & Pouco/nenhum & Teórico & Contabilidade Geral & Uma vez \\
\hline
\end{tabular}




\section{ERRATA}

No artigo "Análise dos traços de tendência de uma amostra das revistas científicas da área de contabilidade publicadas na língua inglesa", com número de DOI: 10.1590/ S1413-92512000000200004, publicado no periódico Caderno de Estudos, 13(24): 5078 , na página 50 :

Onde se lia:

Prof. Dr. Fábio Frezatti

Doutor em Controladoria e Contabilidade - FEA/USP

Professor do Departamento de Contabilidade e Atuária - FEA/USP

Leia-se:

Prof. Dr. Fábio Frezatti

Doutor em Controladoria e Contabilidade - FEA/USP

Professor do Departamento de Contabilidade e Atuária - FEA/USP

Prof. José Alonso Borba

Mestre em Contabilidade - FGV/RJ ou Doutorando em Contabilidade - FEA/USP

Professor do Departamento de Contabilidade - UFSC 